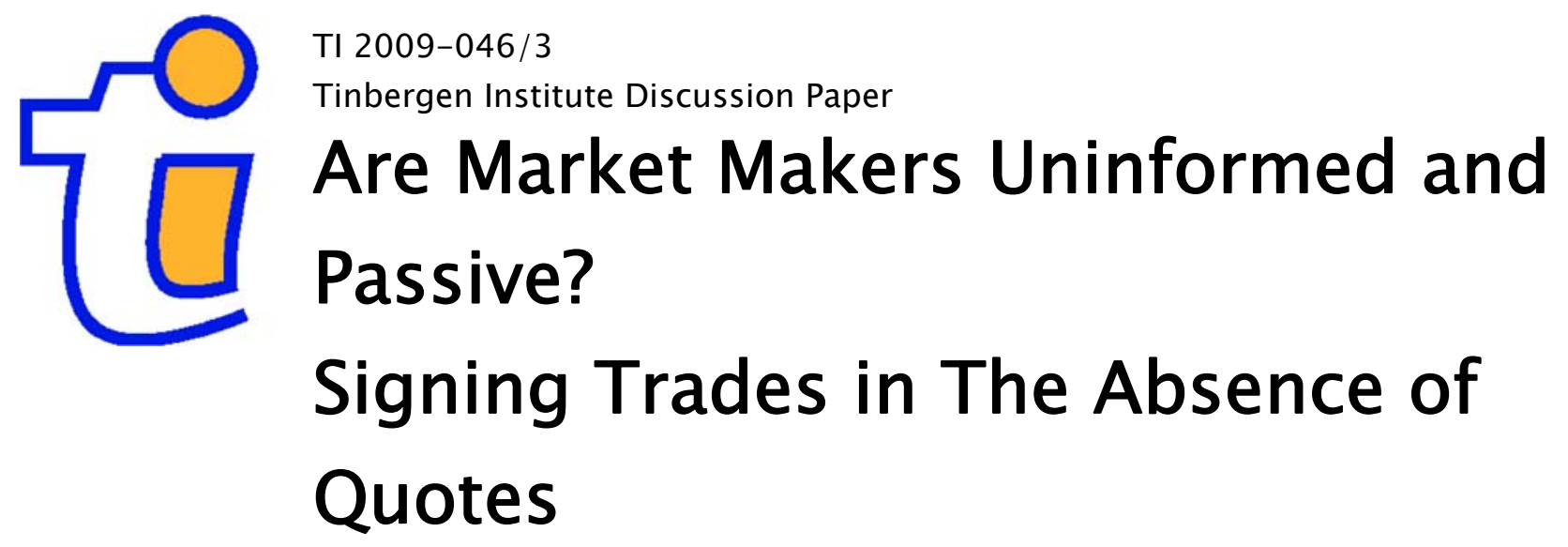

Michel van der Well,2

Albert J. Menkveld3,2

Asani Sarkar4

' Erasmus University Rotterdam, CREATES, ERIM;

2 Tinbergen Institute;

3 VU University Amsterdam;

${ }^{4}$ Federal Reserve Bank of New York. 


\section{Tinbergen Institute}

The Tinbergen Institute is the institute for economic research of the Erasmus Universiteit Rotterdam, Universiteit van Amsterdam, and Vrije Universiteit Amsterdam.

Tinbergen Institute Amsterdam

Roetersstraat 31

1018 WB Amsterdam

The Netherlands

Tel.: +31(0)205513500

Fax: $+31(0) 205513555$

Tinbergen Institute Rotterdam

Burg. Oudlaan 50

3062 PA Rotterdam

The Netherlands

Tel.: + $31(0) 104088900$

Fax: $+31(0) 104089031$

Most TI discussion papers can be downloaded at http://www.tinbergen.nl. 


\title{
Are Market Makers Uninformed and Passive? Signing Trades in the Absence of Quotes
}

\author{
Michel van der Wel* \\ Erasmus University Rotterdam, CREATES, \\ ERIM and Tinbergen Institute \\ vanderwel@ese.eur.nl
}

Albert J. Menkveld

VU University Amsterdam, Tinbergen Institute

albertjmenkveld@gmail.com

\author{
Asani Sarkar \\ Federal Reserve Bank of New York \\ asani.sarkar@ny.frb.org
}

May $2009^{\dagger}$

\footnotetext{
${ }^{*}$ Corresponding author. Address details: Erasmus University Rotterdam, P.O.Box 1738, 3000 DR Rotterdam, Netherlands. Phone number: $+31(0) 10-4081316$.

${ }^{\dagger}$ The views stated here are those of the authors and do not necessarily reflect the views of the Federal Reserve Bank of New York or the Federal Reserve System. We appreciate the comments of Riccardo Calcagno, Dick van Dijk, Thierry Foucault, Borus Jungbacker, Siem Jan Koopman, Andre Lucas, Carsten Tanggaard, Ernst-Ludwig von Thadden, and participants at the Humboldt-Copenhagen conference in Berlin, the NAKE Research Day in Utrecht, the First Erasmus Liquidity Conference in Rotterdam, the Merton H. Miller doctoral seminar at the EFMA and seminars at CREATES, the VU University and the Tinbergen Institute. We are grateful to the Netherlands Organization for Scientific Research (NWO) for a VENI grant and travel support. Michel van der Wel acknowledges the support from CREATES, funded by the Danish National Research Foundation. We are responsible for all errors.
} 


\title{
Are Market Makers Uninformed and Passive? Signing Trades in the Absence of Quotes
}

\begin{abstract}
We develop a new likelihood-based approach to sign trades in the absence of quotes. It is equally efficient as existing MCMC methods, but more than 10 times faster. It can deal with the occurrence of multiple trades at the same time, and noisily observed trade times. We apply this method to a high-frequency dataset of the 30Y U.S. treasury futures to investigate the role of the market maker. Most theory characterizes him as an uninformed passive liquidity supplier. Our results suggest that some market makers actively demand liquidity for a substantial part of the day and are informed speculators. Keywords: market microstructure, signing trades, market makers, treasury futures, discount rate
\end{abstract}

JEL: C22, G14, E44

Financial markets rely on traders willing to supply liquidity to accommodate the trading desire of other traders. In many cases financial market datasets do not specify which of the traders involved in a transaction supplied liquidity, and which demanded it. Determining who is the liquidity demanding party (often referred to as 'signing' trades) is commonly done using econometric techniques. We propose a novel technique to sign trades for markets where there is no quote information available. We apply it to a detailed dataset of the 30 year U.S. treasury futures market to investigate liquidity supply by market makers.

The task of determining the trade initiating party is a challenging one. The difficulty of this task increases in settings where no quotes are available. For markets with quotes the observed transaction price is related to the prevailing bid- and ask-quotes. If a trade takes place closer to the ask (bid) we say the trade is initiated by the buying (selling) party. ${ }^{1}$ For markets without quotes, Hasbrouck (2004) suggests implementing a method based on the Roll (1984) model. Here the observed transaction price is either a half-spread above or below an unobserved efficient price, depending on whether the trade was initiated by the buying or selling party. The proposed technique relies on a Bayesian inference method, the Gibbs Sampler. As this is a simulation based method it is computationally burdensome, and may be too time-consuming for many datasets. For example, our dataset for the U.S. treasury futures market consists of more than 42 million trades.

\footnotetext{
${ }^{1}$ Lee and Ready (1991) is often cited for such kind of approach. Section 1.1 provides a complete overview.
} 
We develop an innovative method for determining whether the buying or selling party initiated a trade. The method we propose follows from the same principles as the Hasbrouck (2004) method. However, as our model relies on likelihood-based methods of time-series models in state space form we greatly reduce the computational burden. Applying Hasbrouck's method to our dataset would require over 40 hours for one model variation to be estimated, whereas the method we suggest requires a little over 110 minutes. ${ }^{2}$ In addition we develop an approximate approach, in which we deal with two other features that are common to financial market datasets but have not yet been dealt with in the existing signing literature. First, the approximate approach can deal with the occurrence of trades that take place at the same time. Second, it allows to analyze settings in which the trade time is observed with noise. This is done in both cases by stacking multiple observations and treating them as equal.

The importance of the new approach goes beyond signing trades. Hasbrouck (2009) applies the Bayesian Hasbrouck (2004) methodology to a daily CRSP dataset ranging a long time span from 1926-2006 to obtain an estimate of the daily spread. Moreover, the Roll (1984) model is used as workhorse model in market microstructure. It is used, e.g., to study informational attributes for the case that one security trades on multiple markets (Hasbrouck (2002) provides an overview of this latter and related settings). Our new fast implementation can be used in these settings to obtain estimates in a framework closer to the original Roll (1984) model.

We apply the method to our treasury futures market dataset to study liquidity demand and supply by market makers. Market makers play an important role in financial markets. They stand ready to buy and sell in order to accommodate the asynchronous arrival of sellers and buyers. Classic inventory models assume that they are risk-averse and therefore need compensation for carrying suboptimal inventory through time. In the process they earn the bid-ask spread to compensate for bearing inventory risk. ${ }^{3}$ Empirically, studies measure inventory control through the rate of inventory mean reversion and results are relatively poor, i.e. half-life of inventory typically is often long relative to what one might expect. ${ }^{4}$

\footnotetext{
${ }^{2}$ The number of times each of the methods needs to run over all the observations causes the difference in required calculation time. Hasbrouck (2004) suggests 10,000 swoops over the data, while our likelihoodbased method requires on average 10 maximum likelihood iterations to estimate the two parameters in which the likelihood is calculated about 6 times. See Section 3.2 for more details on the differences in estimation procedures and calculation times.

${ }^{3}$ The costs associated with the inventory risk is one of the three classic explanations for the bid-ask spread. The other two explanations are information asymmetry (see for example Kyle (1985) and Glosten and Milgrom (1985)) and order processing costs (such as in Roll (1984)). See O'Hara (1995) for an overview.

${ }^{4}$ For example, Hasbrouck and Sofianos (1993) show that it takes long to reduce an inventory position, sometimes up to two months. However, some of the inventory models' predictions are confirmed by data,
} 
Two likely explanations for slow inventory mean-reversion are (i) institutional features of a market that affect market maker behavior and (ii) active position-taking by market makers to speculate on private information. Panayides (2007) provides an example of the first and shows that the New York Stock Exchange specialist is sometimes forced to take on positions due to the Price Continuity rule. Madhavan and Smidt (1993) illustrate that a second reason for slow mean-reversion is speculation. They develop a model where the market maker actively manages inventory and mean-reverts it to a long-run average position, but, at the same time, they show that when he has access to private information he speculates by actively building a short-term position. This could explain the low level of mean-reversion if the econometrician ignores speculation. ${ }^{5}$

In the empirical part of this paper, we explore whether (unconstrained) market makers actively speculate in the sense of Madhavan and Smidt (1993). We examine a large cross-section of 3,384 market makers active on the $30 \mathrm{Y}$ U.S. treasury futures trading pit on the Chicago Board of Trade. ${ }^{6}$ We find evidence of inventory control as the end of day inventory distribution is concentrated around zero. In addition, we find that indeed market makers actively take positions in the course of the day, i.e. they initiate trades that increase their inventory position. When we relate the extent of active position taking to proprietary trading profits we find a significant and positive correlation. This profitable position taking is consistent with active speculation by the market maker. Our results emphasize the need for theoretical models that take the informativeness of the market maker into account, such as the model recently put forward by Boulatov and George (2008).

The current literature provides at best indirect evidence that market makers at times are speculators. Some studies find that the market maker initiates a significant share of his trades (Frino and Jarnecic (2000)) and interpret this as evidence of speculation. Initiation in itself, however, is not the same as speculation as market makers can initiate trades to actively manage their inventory position back to the long-term mean level. A nice illustration of this phenomenon is the 'hot-potato' trading model of Lyons (1997). Locke and Sarajoti (2004) find market maker inventory can be split into a desired and undesired position (from a long-

most notably that market makers do manage inventory toward a target (see for example Manaster and Mann (1996) and Bjønnes and Rime (2005)). Recent evidence, however, shows that inventories mean-revert with half-life ranging from less than one up to several days (see Hendershott and Menkveld (2009)).

${ }^{5}$ One outcome of their model is an equation that explicitly explains today's inventory as the sum of two components: (i) a fraction of yesterday's inventory consistent with inventory management and (ii) an active position on private information. We discuss the equation further in Section 1.

${ }^{6}$ This is the total number of floor traders active in the trading pit over our sample period. Of these the great majority, roughly $85 \%$ on an average day, trades for own account and thus possibly supplies liquidity. That these floor traders are market makers is consistent with, for example, Manaster and Mann (1996) and Chakravary and Li (2003). 
term rational expectations point of view), and that market makers are most aggressive to offset large undesired positions. Manaster and Mann (1996) and Bjønnes and Rime (2005) document strong inventory control but, surprisingly, do not find the expected price effects of inventory. ${ }^{7}$ They conclude that their results are consistent with active speculative position taking by floor traders. Anand and Subrahmanyam (2008) show that intermediaries, a subset of the market makers we study, have information orthogonal to what they could learn from their client flow and account for greater price discovery. And, contrary to all these studies, Chakravary and Li (2003) study market making but do not find evidence in favor of speculation. We add to all of the aforementioned papers, as we are the first to provide direct evidence of active position taking by market makers. Moreover, when we relate this position taking to trading profits we find a positive and significant relation, which suggests that market makers trade for speculative reasons.

Our dataset of the 30Y U.S. treasury futures over the period 1994-1997 to study market maker liquidity supply has three advantages. First, we can identify whether trades are proprietary or on behalf of customers. After signing the trades as buyer- or sellerinitiated this allows us to study not only liquidity supply, but also liquidity demand of the market maker. Second, of the work that focuses solely on the liquidity supplying role of the market maker the majority looks at the New York Stock Exchange Specialist, ${ }^{8}$ who, as was pointed out earlier, is not a pure market maker as he is sometimes restricted by his obligation to smooth transaction prices. Therefore it is more natural to study the market maker in settings where he does not have such an obligation, as in treasury futures markets. Third, an advantage of our dataset over the existing treasury futures market liquidity supply studies is that the maturity we look at has the largest share of trading in one market. Manaster and Mann (1996) and Chakravary and Li (2003) study liquidity supply on the market for the less liquid 13 week bill, for which trading is split between the spot and futures market. When this is case one has to account for trading across markets. We therefore feel our dataset is an appropriate choice to study the issue of liquidity supply and demand by market makers. ${ }^{9}$

The rest of the paper is structured as follows. Section 1 discusses related literature.

\footnotetext{
${ }^{7}$ Demsetz (1968) and Stoll (1978) show that it could be optimal for market makers to not quote symmetrically around the efficient price, but deviate in order to create incentives for liquidity demanders to trade in the direction that brings the market maker inventory back to zero.

${ }^{8}$ See Section 1.2 for a full overview.

${ }^{9}$ For the 13 week bill about $55 \%$ of volume trades on the futures market. For the 30 year bond almost all trading takes place on the futures market, about 95\%. These calculations are based on Fleming and Sarkar (1999). For spot the on-the-run security is taken, for futures the nearby contract. The sample size of both studies illustrate the lower liquidity of the 13 week contract: Manaster and Mann (1996) look at 584 trader days, Chakravary and Li (2003) study only 6 traders for the treasury futures market (though both studies include more data, but from other futures contracts).
} 
In Section 2 we discuss our dataset, provide some institutional background, and provide summary statistics. Section 3 details the method we use to sign the trades in our dataset. In Section 4 we present our empirical findings. Section 5 concludes.

\section{Related Literature}

\subsection{Signing Futures Market Trades}

Our work relates to the literature on classifying trades according to whether they are initiated by the buying or selling party (the so-called 'signing' of trades). For markets with explicit quotes a trade is qualified as being initiated by the buying party if it takes place closer to the ask than the bid (Hasbrouck (1988), Lee and Ready (1991) and Ellis, Michaely, and O'Hara (2000)).

For markets without quotes identifying whether the buying or selling party initiated the trade is more challenging as it is difficult to find a good 'reference' for the observed transaction prices. A tick test can be used, where a trade is labeled as being initiated by the buying party if it is an uptick (i.e. if the transaction price is larger than the previous price). However, this method has the disadvantage that a trade can be incorrectly labeled as buyer-initiated simply due to an unrelated and simultaneous price innovation. Alternatively, Rosenberg and Traub (2007) suggest to use the quotes of a parallel market for the same asset as a reference: to sign futures market trades they use the quote from the forward market. Unfortunately, this is not applicable generally as there needs to be such a parallel market.

Hasbrouck (2004) suggests using a Bayesian methodology (the Gibbs sampler) to explicitly model the price innovation and trade sign. Unlike the aforementioned methods this grounds in economic theory: it is based on the Roll (1984) model. We follow his approach, but suggest a much quicker likelihood based algorithm to sign futures market trades. In addition we develop a method that deals with high-frequency datasets in which it can occur that there are multiple trades occurring at the same second at the same price and that the trade time is observed with noise. 


\subsection{Market Making and Inventory}

Our study of the market maker relates to several strands of literature. First, it relates to the literature that assumes the market maker is an uninformed passive liquidity supplier. For example, in Stoll (1978) the market maker adjusts his quotes depending on his inventory position to get rewarded for the risk of holding a nonzero inventory position. In the adverse selection models of Kyle (1985) and Glosten and Milgrom (1985) the market maker sets prices such that in expectation he has no profits and absorbs the net order flow. In both types of models the market maker is uninformed and a liquidity supplier.

Madhavan and Smidt (1993) are the first to provide an exception to the above setting. They introduce a model in which the market maker is both a dealer and a speculator. Equation (6) in their paper gives the optimal trade quantity of the market maker, and illustrates this dual nature:

$$
I_{t+1}-I_{t}=\beta\left(I_{t}-I^{d}\right)-\frac{1+\beta}{2} x_{t}
$$

with $I_{t}$ the market maker's inventory position at time $t,-1<\beta<0$ a parameter measuring the speed of inventory adjustment, $I^{d}$ the long-term desired inventory position and $x_{t}$ representing the short-horizon investment strategy. Thus in the Madhavan and Smidt (1993) model the optimal trade quantity of the market maker consists of two components: the deviation of his inventory from the long-run desired level and a short-run speculative strategy. In Boulatov and George (2008) liquidity suppliers can also be informed. Specifically, informed traders may choose whether to act as liquidity demanders or suppliers. In case of fully anonymous liquidity provision the informed act exclusively as liquidity suppliers. If there is less than full anonymity some informed traders choose to provide liquidity while others demand liquidity. ${ }^{10}$

Second, we relate to empirical studies of liquidity supply and inventory management. The great majority of these papers look at the Specialist on the New York Stock Exchange, with other studies looking at the U.S. treasury market, the exchange rate market, the London Stock Exchange and option data (see Comerton-Forde et al. (2009) for references). In most of the papers there is at best weak evidence for the empirical predictions of the inventory models. Manaster and Mann (1996) and Bjønnes and Rime (2005) do document strong evidence of inventory control by market makers. Surprisingly however, they do not find

\footnotetext{
${ }^{10}$ The empirical evidence in Hendershott, Jones, and Menkveld (2007) shows that indeed suppliers seem to update quotes based on information.
} 
price effects of the inventory positions. They interpret this as being consistent with active position taking by floor traders. In this paper we provide direct evidence to support this conjecture.

\section{Data and Institutional Background}

To study the market maker and illustrate our signing algorithm we analyze trading in the $30 \mathrm{Y}$ U.S. treasury futures pit. This instrument trades on the Chicago Board of Trade (CBOT). On the trading floor (the 'pit') traders ('floor traders') gather between 8:20 a.m. and 3:00 p.m. Eastern Time. Trading takes place through the open outcry method: prices are negotiated by shouting out orders and indicating direction and quantity using hand signals.

We look at the 30Y maturity (instead of, e.g., the 5Y) as this is the maturity where volume is most concentrated on one exchange. For the $30 \mathrm{Y}$ maturity about $95 \%$ takes place on the futures market and $5 \%$ on the spot, while for the $5 \mathrm{Y}$ bond this is $24 \%$ and $76 \%$ respectively (see Fleming and Sarkar (1999)). In addition, in our sample period of 19941997 electronic trading is still limited. Thus, by looking at the $30 \mathrm{Y}$ treasury futures we have a setting where we observe almost all trading, and minimize the risk of missing offsetting trades in the other market or electronically. At each moment in time multiple treasury bond futures contracts with different expiry months are traded. We focus on the most nearby as this is the most liquid of these (see Fleming and Sarkar (1999)).

Our dataset records all trades taking place on the futures pit. For each trade are recorded: the time of the trade; a buy/sell indicator; trade quantity (in contracts); trade price; a floor trader identifier and a customer type indicator (CTI). Floor traders have to report their trades in 15 minute brackets. A timing algorithm (the Computerized Trade Reconstruction) is used to time the reported trades to their nearest second. Though this may be noisy we believe this timing is fairly accurate. ${ }^{11}$ It is used by the Commodity Futures Trading Commission (CFTC) for regulation purposes, and is used in, e.g., the studies of Fishman and Longstaff (1992) and Manaster and Mann (1996).

\footnotetext{
${ }^{11}$ In addition, we apply several data filters. First, we focus on 'regular' trades: we remove trades that are, e.g., indicated to be spread trades. Second, we remove trades that show an unusual transaction pattern. Specifically, if a transaction return of more than $0.25 \%$ is followed by a return in the opposite direction also larger than $0.25 \%$ we expect these trades to suffer from serious timing error and eliminate it. In total we remove $1.44 \%$ of all trades with these two filters.
} 
The CTI indicates for each trade whether it is a trade for the own account of the floor trader (a 'proprietary' trade), or on behalf of another party. In particular, we have the following four codes: CTI1: proprietary trade; CTI2: trade for clearing member's house account; CTI3: trade for another member present at the floor; CTI4: a trade for (offexchange) customers. Consistent with earlier futures market studies (such as Fishman and Longstaff (1992), Manaster and Mann (1996) and Chakravary and Li (2003)) we restrict attention to CTI1 and CTI4 trades as they represent most trading volume. Since both parties report a trade the trades are double counted. For example, a trade between two market makers each trading for own account appears twice in our dataset with both times the same quantity, price and CTI but different buy/sell indicator and floor trader identifier.

Following the futures market literature (see for example Fishman and Longstaff (1992), Manaster and Mann (1996) and Chakravary and Li (2003)) we use the CTI codes to identify three groups of floor traders in our data. On a daily basis we identify traders that only trade on behalf of customers (we label these as 'brokers'), traders that only trade for own account ('locals', or local traders) and traders that do both ('duals', or dual traders). ${ }^{12}$ It is important to distinguish these groups, as recent studies find that order flow coming from the customers of dual traders, the end-users in the economy, provides information orthogonal to that from the macroeconomic news (Menkveld, Sarkar, and Van der Wel (2007)), and customer flow may even predict macroeconomic variables (Evans and Lyons (2008)). Thus, compared to the local traders, the dual traders have an additional signal which they can use to update their beliefs of the value of the asset.

Table 1 provides some summary statistics for these groups. Important to note is that of these three groups the locals and duals trade for own account, and are the market makers in this setting. On an average day there are 521 traders active, each generating an average volume of 807 contracts for own account and 793 contracts on behalf of customers. This illustrates the enormous activity of this market: on an average day 357 thousand contracts are traded for own account, and 184 thousand contracts are traded on behalf of customers. Of the 521 traders active on an average day 288 are local traders, 155 dual traders and 78 brokers. Thus, on an average day in our sample 443 floor traders provide market making services.

We combine our above treasury futures dataset with a dataset on macroeconomic announcements from the International Money Market Services (MMS). As many studies

\footnotetext{
${ }^{12}$ Following the literature we allow for a $2 \%$ error margin for this classification (see for example Fishman and Longstaff (1992) and Chakravary and Li (2003)). That is, if daily volume for a trader on a day consists of more than $98 \%$ (less than $2 \%$ ) proprietary volume we label him a local (broker), otherwise a dual.
} 


\section{Table 1: Summary Statistics}

This table shows the trading activity for locals, duals and brokers on the market for the $30 \mathrm{Y}$ treasury futures in 1994-1997. We classify traders at the daily basis, and label a trader to be a local (broker) if more than $98 \%$ (less than 2\%) of his trades are for own account, otherwise he is a dual. For these three groups we show the average number of days a trader is active, the average number of traders active on a day, the total number of trading days and the average daily volume per trader. In addition we show these for the three groups of traders combined (All Traders). The column Sample shows the total number of days and number of traders observed in our sample.

\begin{tabular}{|c|c|c|c|c|c|}
\hline \multicolumn{6}{|c|}{ Summary Statistics - Trader Activity } \\
\hline & \multicolumn{3}{|c|}{ All } & \multirow[b]{2}{*}{ Duals } & \multirow[b]{2}{*}{ Brokers } \\
\hline & Sample & Traders & Locals & & \\
\hline \multicolumn{6}{|l|}{ Avg \#days a trader is active } \\
\hline all days & 1,005 & 155 & 173 & 130 & 27 \\
\hline announcement days & 377 & 60 & 67 & 50 & 11 \\
\hline nonannouncement days & 350 & 52 & 58 & 44 & 9 \\
\hline \multicolumn{6}{|l|}{ Avg \#traders active per day } \\
\hline all days & 3,384 & 521 & 288 & 155 & 78 \\
\hline announcement days & & 535 & 296 & 157 & 82 \\
\hline nonannouncement days & & 501 & 276 & 150 & 74 \\
\hline \multicolumn{6}{|l|}{ Total number of trading days } \\
\hline all days & & 523,540 & 289,354 & 155,381 & 78,805 \\
\hline announcement days & & 201,571 & 111,645 & 59,199 & 30,727 \\
\hline nonannouncement days & & 175,349 & 96,674 & 52,664 & 26,011 \\
\hline \multicolumn{6}{|c|}{ Average daily volume per trader } \\
\hline \multicolumn{6}{|l|}{ For own account } \\
\hline all days & & 807 & 1,070 & 318 & \\
\hline announcement days & & 903 & 1,198 & 345 & \\
\hline nonannouncement days & & 682 & 897 & 288 & \\
\hline \multicolumn{6}{|l|}{ For customers } \\
\hline all days & & 793 & & 921 & 541 \\
\hline announcement days & & 894 & & 1,048 & 596 \\
\hline nonannouncement days & & 667 & & 766 & 467 \\
\hline
\end{tabular}


find that these scheduled releases of news significantly affect returns, volatility, volume and information asymmetry ${ }^{13}$ we expect that they may also matter for purposes of liquidity supply and demand, as market makers anticipate these announcements and their effect on markets. We consider a broad set of 25 macro announcements such as the PPI, CPI and Nonfarm Payroll Employment figures (which have previously been studied by, e.g., Green (2004), Pasquariello and Vega (2007) and Menkveld, Sarkar, and Van der Wel (2007)) that occur throughout the trading day at fixed times, such as at 8:30 a.m. ET and 10:00 a.m. ET. For each macro announcement an expectation of market participants is recorded, together with the first released (i.e. not revised) figure. Consistent with the aforementioned studies, we focus on the 8:30 announcements as this is where the most significant announcements are. Using the announcement data we split our sample in two groups. We look at days at which there is one or more 8:30 announcement, and days at which there are no announcements at 8:30. To make sure the 8:30 announcement is driving the results we are careful to take out days with other announcements that take place in the morning (that is, at 9:15 and 10:00).

Table 1 also provides summary statistics for these announcement and nonannouncement days. Of the total 1,005 days in our sample we find there are 377 announcement days, and 350 nonannouncement days. We see a clear increase in trading activity both in average volume traded and number of traders on announcement days compared to nonannouncement days. For example, on average on announcement days there are 535 traders active, while on nonannouncement days there are 501 traders, $6.4 \%$ less.

For each trader we have a record of all his trades in the $30 \mathrm{Y}$ treasury futures, plus the direction of each of these trades. We use this to obtain the inventory for each trader. Consistent with the previous literature (see for example Manaster and Mann (1996)) we do this under the assumption that floor traders close out the day with zero inventory. ${ }^{14}$ In Figure 1 we plot the end of day inventory that is obtained using this assumption. From the figure it is clear that end of day inventory is indeed centered around zero. The most common end of day inventory position is a flat position. Of the nonzero positions most are below 15 contracts in absolute terms, which is small compared to the average market maker's trade size of 807 contracts. This suggests that the assumption that is used to construct the

\footnotetext{
${ }^{13}$ See, e.g., Ederington and Lee (1993), Fleming and Remolona (1999), and Andersen, Bollerslev, Diebold, and Vega (2007) for evidence on the effects of macroeconomic announcements on returns, volatility and trading volume. Green (2004), Pasquariello and Vega (2007) and Menkveld, Sarkar, and Van der Wel (2007) document changes in information asymmetry after macroeconomic announcements.

${ }^{14}$ There are some limitations to this way of calculating inventories. As we focus on CTI1 and CTI4 trades we miss possible CTI2 and CTI3 trades of market makers. In addition we only have a record of the trades in the 30Y treasury futures, and not in other markets. But similar to Manaster and Mann (1996), we believe the current method provides the most accurate estimate of inventories.
} 


\section{Figure 1: End of Day Inventory}

We show the end of day inventory for floor traders active in the 30Y treasury futures in 1994-1997. For each day the end of day inventory position is calculated only for traders that were active on that day, assuming a zero inventory position at the beginning of the day. The figure shows the histogram of the end of day inventories, with an estimated empirical distribution.

End of Day Inventory, Empirical Distribution

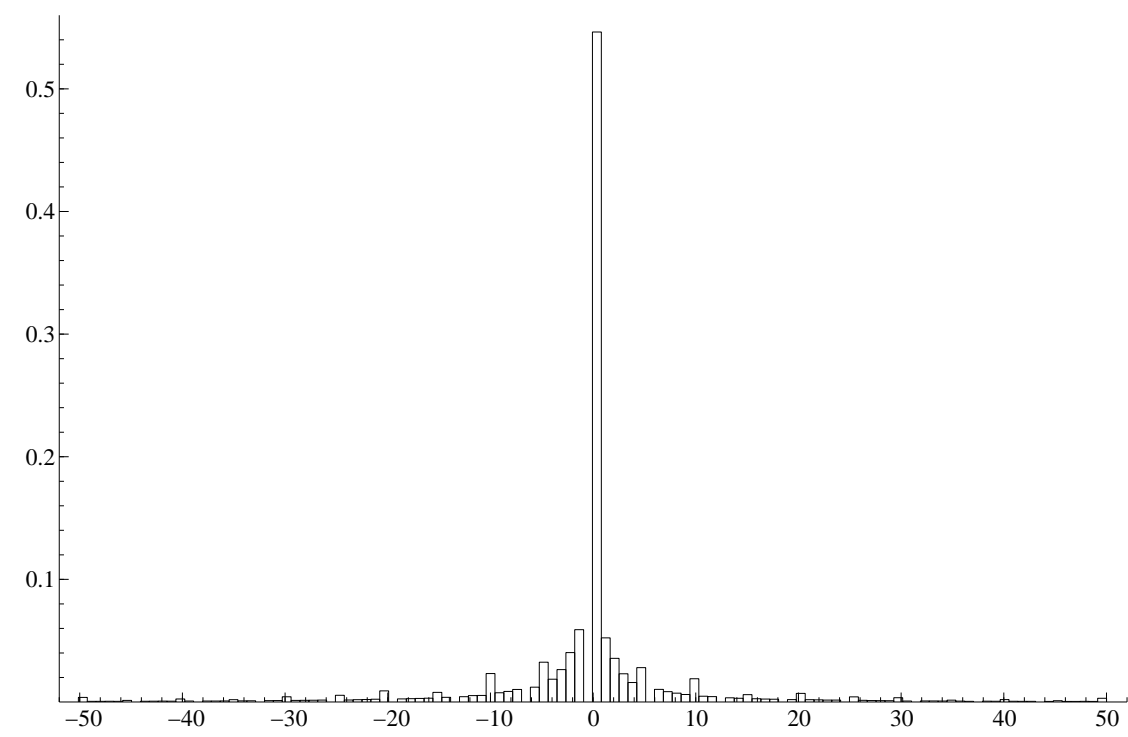


inventory series is a reasonable one.

\section{Signing Futures Market Trades}

An important variable that is not available in many datasets is the trade sign, which specifies which of the parties initiated a trade. Motivated by the above typical and rich futures market dataset, we develop an efficient algorithm to estimate this sign.

\subsection{Methodology}

Signing the trades in a dataset amounts to determining for each trade whether it is initiated by the buying or selling party. For markets with explicit bid and ask quotes algorithms for this challenging task are available, an often employed technique that relates the transaction price to the average of the bid and ask quote (the 'midquote') is put forward by Lee and Ready (1991). For markets without quotes the identification is an even more challenging task. Whereas in the former case the observations consist of transaction prices and both bid and ask quotes, for the latter only the transaction prices are observed.

Hasbrouck (2004) proposes a new Bayesian methodology to deal with the challenge of estimating the unobserved sign of the trades from the observed transaction prices. The methodology is based on the Roll (1984) model of the bid-ask spread. ${ }^{15}$ In this model the logarithm of the unobserved efficient price $m_{t}$ evolves as a random walk:

$$
m_{t}=m_{t-1}+u_{t}, \quad u_{t} \sim N\left(0, \sigma_{u}^{2}\right)
$$

The actually observed log transaction prices $p_{t}$ are either above or below this unobserved efficient price, depending on whether the trade is initiated by the buyer or the seller of the transaction. If we let $q_{t} \in\{-1,+1\}$ denote the direction of a trade, with +1 a buyer-initiated trade and -1 a seller-initiated trade, and $c$ the transaction costs we can write the observed

\footnotetext{
${ }^{15}$ In addition, Hasbrouck (2004) suggests several extensions to the Roll (1984) model that can be estimated in the Bayesian framework he proposes. As our main purpose is the signing of trades we choose a standard setting and therefore remain in the set-up of the Roll (1984) model. Note that in addition to this standard setting, we also develop an alternative method to sign futures trades that allows for more flexibility and that also our standard setting can be extended in multiple directions.
} 
$\log$ transaction price as:

$$
p_{t}= \begin{cases}m_{t}+c, & \text { if } q_{t}=+1, \\ m_{t}-c, & \text { if } q_{t}=-1,\end{cases}
$$

or simply $p_{t}=m_{t}+c q_{t}$.

Hasbrouck (2004) suggests a Markov Chain Monte Carlo (MCMC) methodology (the Gibbs Sampler), in which iteratively draws from the parameters $c$ and $\sigma_{u}^{2}$ are obtained, together with draws for the unobserved time series of signs $q_{t}, t=1, \ldots, n$. For a large number of draws the simulated distribution will be equal to the desired joint posterior distribution of the parameters and sign time series, conditional on the observed prices. An obvious disadvantage of these simulation based techniques is that they are computationally expensive and require a lot of simulations to obtain convergence. As we have over 42 million observations this MCMC technique requires long computation time.

Instead of the above Bayesian methodology we propose to estimate the Roll (1984) model parameters $c$ and $\sigma_{u}^{2}$ and the series of trade initiating signs $q_{t}$ in a State Space Form (SSF) framework. This class of time-series models builds on the idea that an observed series can be explained by several unobserved components. ${ }^{16}$ If we write the Roll (1984) model in this framework we obtain:

$$
\begin{aligned}
p_{t} & =m_{t}+c q_{t}, & & q_{t} \in\{-1,+1\}, \\
m_{t} & =m_{t-1}+u_{t}, & & u_{t} \sim N\left(0, \sigma_{u}^{2}\right) .
\end{aligned}
$$

As the $q_{t}$ are not Gaussian but binary distributed (assumed to be initiated by the buying or selling party with equal probability, an assumption that can easily be relaxed in this framework) this is not a standard linear Gaussian state space model. However, since $q_{t}$ can only take on two values this model can be seen as a special case of state space models with regime switching. Kim and Nelson (1999) discuss the implementation of regime switching models in the state space framework, and show that it is a combination of the Kalman Filter for SSF models and the Hamilton (1989) filter for regime switching models. By implementing the recursions of this algorithm we obtain a likelihood value, which we can maximize using standard optimization techniques. The appendix provides details of how we implement these recursions for the Roll (1984) model.

\footnotetext{
${ }^{16}$ See Durbin and Koopman (2001) for an introduction. Menkveld, Koopman, and Lucas (2007) also look at Gaussian state space models in a market microstructure context; Glosten and Harris (1988), Harris (1990) and Hasbrouck (1999) employ non-Gaussian state space methods.
} 
There are a few additional issues when applying our State Space Form Regime Switching (SSF-RS) signing methodology to financial market data. As is the case for our dataset, for very actively traded instruments it occurs that there are multiple trades at the same second. In fact, it can even occur that in the futures pit there are trades at different prices in the same second. For example, in our dataset this happens at more than $1 \%$ of all seconds at which trading takes place. ${ }^{17}$ Since in the Roll (1984) model the transaction cost and efficient price innovation and thus the sign does not depend on quantity, we summarize the information of all trades in this second to one single observation. In addition, transaction times can be observed with noise. This is something of particular importance for futures markets, and as we pointed out in Section 2, is also the case for our data as the time stamps of the trades are obtained using the Computerized Trade Reconciliation algorithm. Though we believe the stamps are fairly accurate they are noisy to some extent and they can not be used to determine the exact sequence of transactions.

To deal with these issues, which are not addressed in Hasbrouck (2004), we implement an alternative signing algorithm. This algorithm is also based on the state space model, but now we aggregate all trades within a certain interval by stacking them. We approximate the Roll (1984) model of equation (3) with a linear Gaussian state space model:

$$
\begin{array}{rlrl}
\vec{p}_{t} & =\iota m_{t}+\vec{v}_{t}, & & \vec{v}_{t} \sim N\left(0, I \sigma_{v}^{2}\right), \\
m_{t}=m_{t-1}+u_{t}, & & u_{t} \sim N\left(0, \sigma_{u}^{2}\right),
\end{array}
$$

with $\vec{p}_{t}$ a vector collecting all price observations at time $t, \iota$ a vector with ones that is of the same dimension as $\vec{p}_{t}, \vec{v}_{t}$ a vector collecting the noise elements in the observation equation and $I$ the unit matrix. In this model we have for each of the elements $i$ in the noise vector $\vec{v}_{t}$ mean $\mathbb{E}\left[v_{i t}\right]=\mathbb{E}\left[c q_{i t}\right]=0$ and variance $\mathbb{V}\left[v_{i t}\right]=\mathbb{V}\left[c q_{i t}\right]=c^{2}$. As we now do not need the additional calculations of the Hamilton (1989) filter we can straightforwardly implement a multivariate version of this model using fast standard state space form computing packages. This allows to aggregate the trades within a certain interval (10 seconds for example, or 1 minute) by creating a multivariate price vector for each time. The fact that in the above algorithm the size of the price vector varies is not a problem for SSF models as this class of models is particularly well-suited for models with missings. In addition, one can use this approach to deal with the situation that in some seconds there are trades occurring at different prices.

\footnotetext{
${ }^{17}$ These time periods of high trade intensity might well be disproportionally important for price discovery.
} 


\subsection{Simulation Study}

Table 2: Signing Futures Market Trades - Simulation Study

This table shows the simulation results for signing trades in the absence of quotes. We compare the output from the State Space Form (SSF) Regime Switching signing algorithm we propose to the State Space Form Approximation method, Hasbrouck's (2004) MCMC method, the method of moments and a tick test (in which a trade is labeled as being initiated by the buying party if it is an uptick). The parameters we use for our data generation process (True Parameters) are chosen such that they are close to values actually observed in the data. For the five signing methods we report the mean and standard deviation (St.Dev.) of the half-spread $c$ and the efficient price variance (Eff Price Var), the percentage of trades that are signed correctly, the root mean squared error (RMSE, x1,000,000) of the smoothed efficient price versus the true value and the time needed to run the algorithm (in seconds). For the simulation 50 observations and 100 replications are used.

\begin{tabular}{|c|c|c|c|c|c|c|c|}
\hline \multicolumn{8}{|c|}{ Signing Futures Market Trades - Simulation Study } \\
\hline & \multicolumn{2}{|c|}{$\begin{array}{c}\text { Half-Spread } \\
(c ; \mathrm{x} 1,000)\end{array}$} & \multicolumn{2}{|c|}{$\begin{array}{c}\text { Eff Price Var } \\
\left(\sigma_{u}^{2} ; \mathrm{x} 1,000,000\right)\end{array}$} & \multirow{2}{*}{$\begin{array}{l}\text { \% Sign } \\
\text { Correct }\end{array}$} & \multirow{2}{*}{$\begin{array}{c}\text { RMSE } \\
\text { of } m_{t}\end{array}$} & \multirow{2}{*}{$\begin{array}{l}\text { Calc } \\
\text { Time }\end{array}$} \\
\hline & Mean & St.Dev. & Mean & St.Dev. & & & \\
\hline True Parameters & 0.200 & & 0.010 & & & & \\
\hline Method of Moments & 0.199 & 0.034 & 0.009 & 0.019 & & & 0.0 \\
\hline SSF Regime Switching & 0.199 & 0.011 & 0.010 & 0.002 & 95.7 & 0.290 & 0.4 \\
\hline SSF Approximation & 0.089 & 0.036 & 0.041 & 0.007 & 95.1 & 0.550 & 0.0 \\
\hline Hasbrouck MCMC & 0.153 & 0.046 & 0.036 & 0.019 & 95.6 & 0.422 & 3.9 \\
\hline Tick Test & & & & & 73.6 & & 0.0 \\
\hline
\end{tabular}

Table 2 provides results from a simulation study of the accuracy and speed of the various signing algorithms. For a number of replications (100 in this set-up) we generate a fixed number of observations (chosen to be 50 here) with Roll (1984) as the Data Generating Process (DGP). For each of these replications we estimate the parameters of the Roll model and the sign (buyer- or seller-initiated) of each trade. We compare the following methods: the State Space Form Regime Switching (SSF-RS) method, the SSF Approximation (SSFApprox) method and Hasbrouck's (2004) MCMC (H-MCMC) method. In addition, we compare the parameter estimates to those obtained from the method of moments, where the distributional properties of the Roll model are used to obtain estimates of $c$ and $\sigma_{u}^{2}$. We also compare the trade sign to a tick test, in which a trade is considered to be buyer-initiated if it is an uptick. 
We find that the method of moments, SSF Regime Switching and Hasbrouck's method all provide good estimates of the Roll model parameters. The results for the SSF Regime Switching and Hasbrouck's method are very similar. For some parameter values and number of observations our SSF-RS method performs slightly better, for other parameter values and number of observations the H-MCMC method performs a bit better. ${ }^{18}$ The SSF Approximating method performs very poor to estimate the model parameters. ${ }^{19}$

In terms of estimating the sign of the trades we see both the SSF Regime Switching method and Hasbrouck's MCMC method perform very well, with an accuracy of over $95 \%$ and greatly outperforming the tick test. The MCMC and SSF-RS methods provide the most accurate results, signing at least another extra $0.5 \%$ of trades correct compared to the competing methods. Interestingly, while the SSF Approximating method performs poor in obtaining the model parameters, it seems to work very well for signing trades.

In terms of time there is a clear difference between the SSF methods and the MCMC method. Hasbrouck's MCMC method is more than 10 times slower than the SSF Regime Switching method. As the MCMC method relies on simulation methods more loops over the data are needed. For example, taking 10,000 swoops (as Hasbrouck recommends) requires $10,000 * n$ calculations. The Maximum Likelihood $(M L)$ calculations based on the SSF Regime Switching method require less. On average 10 iterations in the ML procedure are needed, in which on average 6 times the likelihood has to be calculated. Due to its smoothing nature the loop needs to be forward and backward, so must be multiplied by 2 . Therefore on average the ML method requires about $10 * 6 * 2 * n=120 * n$ calculations and is indeed a lot quicker. The SSF Approximation method provides the quickest results. ${ }^{20}$

Overall there is a case to be made for both of the SSF signing methods and the MCMC method when the main interest is obtaining the trade signs. As our dataset contains many trades we prefer to take one of the quicker methods that is also nested in economic

\footnotetext{
${ }^{18}$ From the results reported in the table it may seem that the Hasbrouck (2004) MCMC method is more biased and less efficient than the SSF Regime Switching method. However, this is due to the chosen number of swoops and burn-in in the MCMC method. With a greater burn-in results similar to the SSF-RS can be obtained with the H-MCMC method, though this will add to the calculation time.

${ }^{19}$ We believe that the bias originates in, in a way, the approximating distribution having fatter tails. That is, the fourth moment of the approximating normal distribution is $3 \sigma_{v}^{4}$, whereas it is $c^{4}$ for the true distribution.

${ }^{20}$ The difference in calculation time between the state space form regime switching and approximating algorithm is however partially due to the underlying code. The regime switching method is implemented in Ox (see Doornik (1998)), while the SSF Approximation method uses the functions from the SsfPack (see Koopman, Shephard, and Doornik (1999)) which are programmed in (the quicker) programming language C. Note that this does not explain the difference between the regime switching and the Hasbrouck (2004) MCMC method as both of these are implemented in Ox. That difference is caused by the former being based on maximum likelihood methods and the latter on simulation methods.
} 
theory, and employ the SSF Regime Switching method. In addition we use the SSF Approximation method for robustness. This latter method is interesting in itself, as it is not only quick but also allows to deal with the noisily observed trade times and the occurrence of multiple trades at the same time.

\subsection{Results}

Figure 2 illustrates how we apply the SSF Regime Switching signing methodology to the data. In the top figure we plot the raw data: the observed transaction prices. Using these observations we obtain an efficient price series that is estimated based on all data (i.e. the smoothed estimate), which is also plotted in the top figure, and a smoothed probability of the trade begin initiated by the buying party. In general we see that our signing methodology acts in the same way as the Lee and Ready (1991) methodology for signing trades when a bid-ask quote is available. In the latter case a trade is considered to be buyer-initiated if it is above the midquote, whereas we label a trade to be initiated by the buying party if it takes place above the smoothed efficient price. Thus in both cases an estimate of the underlying true price is obtained, in the former the midquote and in the latter the smoothed efficient price, around which transactions take place.

In Table 3 we provide some statistics of the results of the signing algorithm on a subset of our dataset. The sign we obtain with our SSF Regime Switching methodology agrees with Hasbrouck's method about $87 \%$ of all observations, and between $82 \%$ and $89 \%$ with the SSF Approximating method. Moreover, our concerns with calculation time seem to be justified: for an average day Hasbrouck's methodology requires more than 2 minutes, while our alternative SSF methods require less than 7 seconds.

We obtain a half-spread estimate of about 0.15. Following the calculations in Hasbrouck (2004) we transform this into a dollar figure by multiplying this estimate with the average transaction price. As the transaction price is roughly $\$ 110$ in 1994-1997, we get a spread estimate of $0.15^{*} 2^{*} \$ 110=\$ 33$. This is very close to the tick size on the market, which is $\$ 31.25$ (see www.cbot.com). This adds further support to the reliability of the signing algorithm. 
Figure 2: Signing Futures Market Trades - Example for 1995/01/03

This figure illustrates how the State Space Form Regime Switching (SSF-RS) signing algorithm is applied to the data. The observations consist of the sequence of the prices reported on January 3, 1995. If multiple trades are observed in the same second at the same price we consider this to be one observation. In the top plot the first 100 reported prices are indicated with crosses. The smoothed efficient price series obtained using the SSF-RS methodology is given by the solid line. The bottom plot gives the smoothed probability that the trade is initiated by the buying party for the first 100 observations. We label a trade as 'buyer-initiated' if this probability is greater than 0.5 .
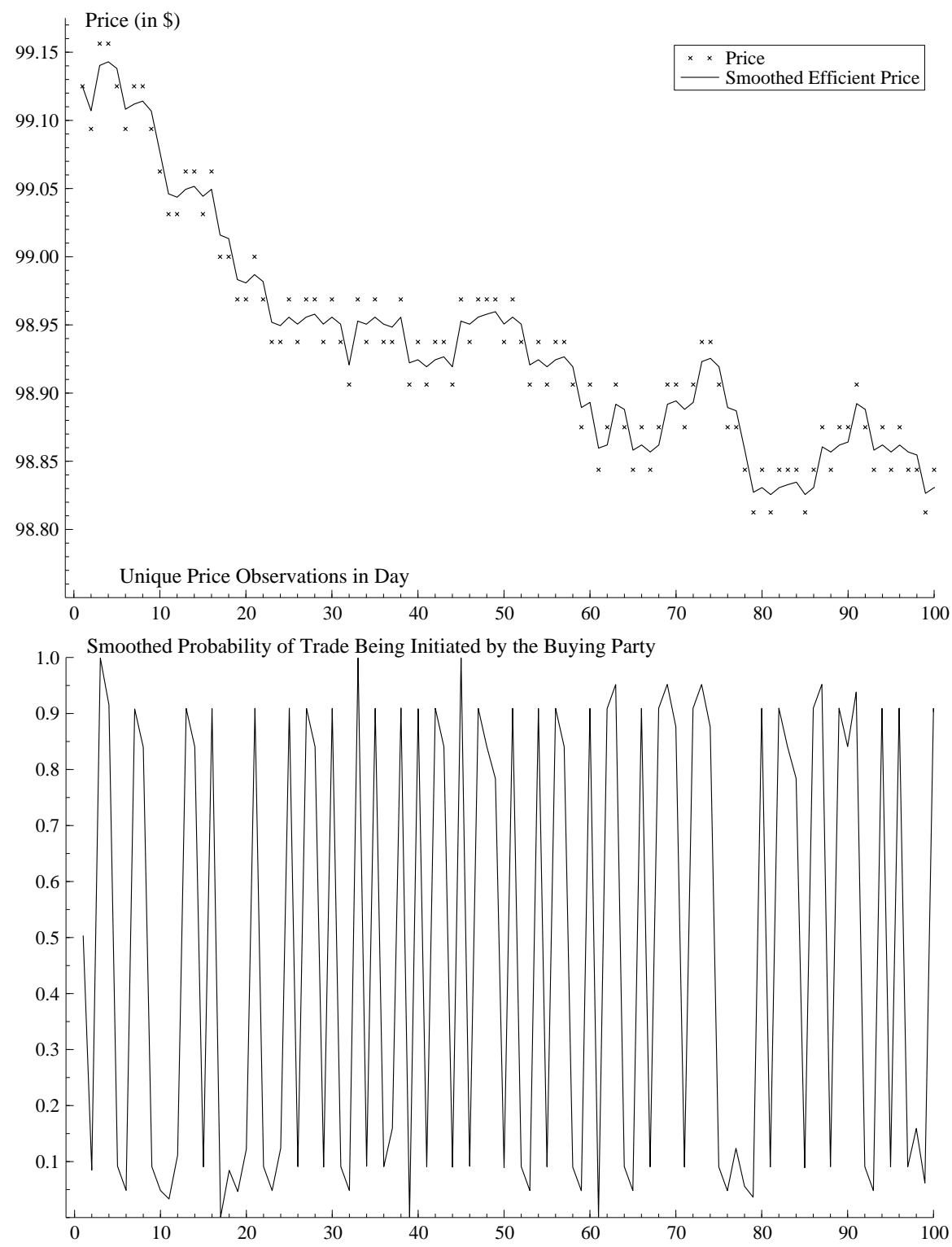


\section{Table 3: Signing Futures Market Trades - Results}

This table shows the results for signing the futures market trades on the market for the 30Y treasury futures in 1994-1997 for 10 days in our dataset. We compare the output from the State Space Form (SSF) Regime Switching (SSF-RS) signing algorithm we propose to the State Space Form Approximation method with aggregation of both 10 and 60 seconds and Hasbrouck's (2004) MCMC method. We show the mean and standard deviation (St.Dev.) of the half-spread $c$ and the efficient price variance (Eff Price Var), the percentage of trades that are labeled the same as the SSF-RS method and the average time needed to obtain these results for one day (in seconds).

\begin{tabular}{|c|c|c|c|c|c|c|}
\hline \multicolumn{7}{|c|}{ Signing Futures Market Trades - Results for 10 Days } \\
\hline & \multirow{2}{*}{\multicolumn{2}{|c|}{$\begin{array}{c}\text { Half-Spread } \\
(c ; \mathrm{x} 1,000)\end{array}$}} & \multirow{2}{*}{\multicolumn{2}{|c|}{$\begin{array}{c}\text { Eff Price Var } \\
\left(\sigma_{u}^{2} ; \mathrm{x} 1,000,000\right)\end{array}$}} & \multirow{2}{*}{$\begin{array}{l}\text { \% Sign } \\
\text { Same as } \\
\text { SSF-RS }\end{array}$} & \multirow{2}{*}{$\begin{array}{l}\text { Calc } \\
\text { Time }\end{array}$} \\
\hline & & & & & & \\
\hline SSF Regime Switching & 0.158 & 0.002 & 0.017 & 0.004 & & 6.7 \\
\hline SSF Approx (10s) & 0.091 & 0.030 & 0.042 & 0.005 & 89.1 & 1.4 \\
\hline SSF Approx (60s) & 0.192 & 0.071 & 0.089 & 0.035 & 81.9 & 0.3 \\
\hline Hasbrouck MCMC & 0.157 & 0.003 & 0.019 & 0.005 & 86.7 & 143.3 \\
\hline
\end{tabular}

\section{Empirical Results}

Here we discuss our empirical results that we obtain after we apply our signing methodology to the data described in Section 2. We first look at how much of the market maker trades are initiated by themselves. Then we look into the cross-section of market makers, and relate the percentage of their trades that they initiate to their profits from trading.

\subsection{Initiated Trades of the Market Makers}

To study the liquidity supply role of market makers we first examine what portion of their trades they initiate. As described in Section 2, there are three groups of floor traders active on the $30 \mathrm{Y}$ treasury futures market. These are the local traders, who only trade for their own account, the dual traders, who trade for own account and on behalf of customers, and brokers, who only trade on behalf of customers. Of these the first two provide market making services, and these are the groups that we focus on in this study. The difference between these two is, besides possible trader fixed effects, the information set: in addition to the publicly available information the dual traders observe the customer trades they bring to 
the market, from which they can also make inferences. Due to this, we split the groups of market makers into locals (no customer trades) and duals (also customer trades) and show results separately for these groups. In addition, we compare the results for days with macroeconomic announcements with those for days without macroeconomic announcements. Following the discussion in Section 2, the market is aware that information will arrive on announcement days and so it is interesting to see whether that additional information leads to changes in trader behavior.

\section{Figure 3: Percentage of Trades Initiated by Market Makers}

These figures show the intraday pattern of the percentage of proprietary trades of locals (A) and duals (B) that they initiate. We classify traders at the daily basis, and label a trader to be a local (broker) if more than $98 \%$ (less than $2 \%$ ) of his trades are for own account, otherwise he is a dual. We sign data according to our State Space Form Regime Switching methodology and match the obtained buyer- and seller-initiated indicator with the buy and sell indicator from our dataset. If they agree we classify the trade as being initiated by the market maker. For each day and trader group we calculate the percentage of total proprietary trades that they initiate, we label this as \%initiated trades. The solid (dashed) lines show the intraday pattern for announcement (nonannouncement) days, the solid vertical lines represent the 8:30-8:45 announcement interval. An open (closed) circle indicates a significant difference between announcement and nonannouncement days at the $5 \%(1 \%)$ level.

(A) \%Initiated Trades of Locals

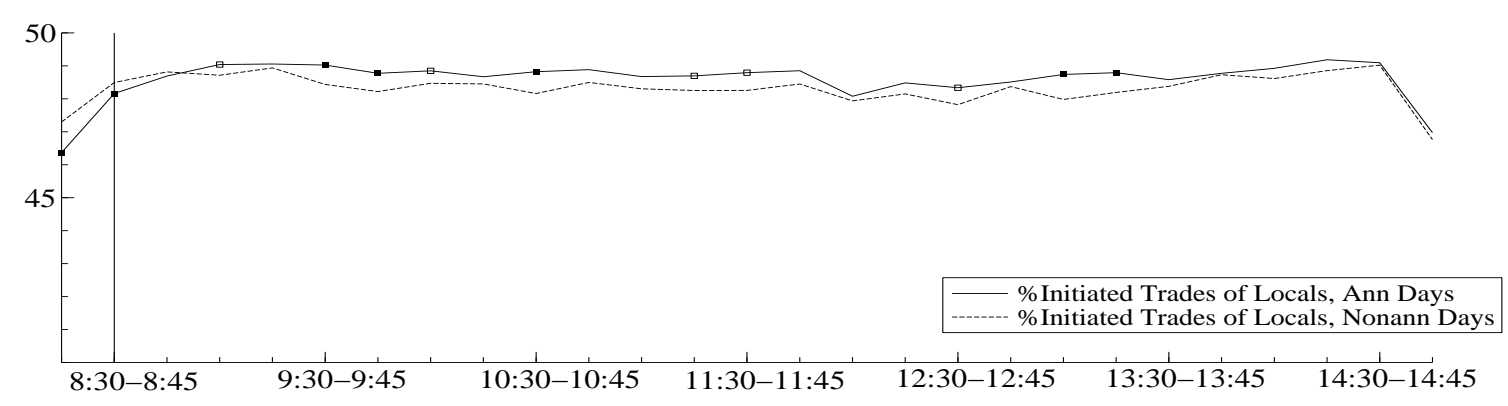

(B) \%Initiated Trades of Duals

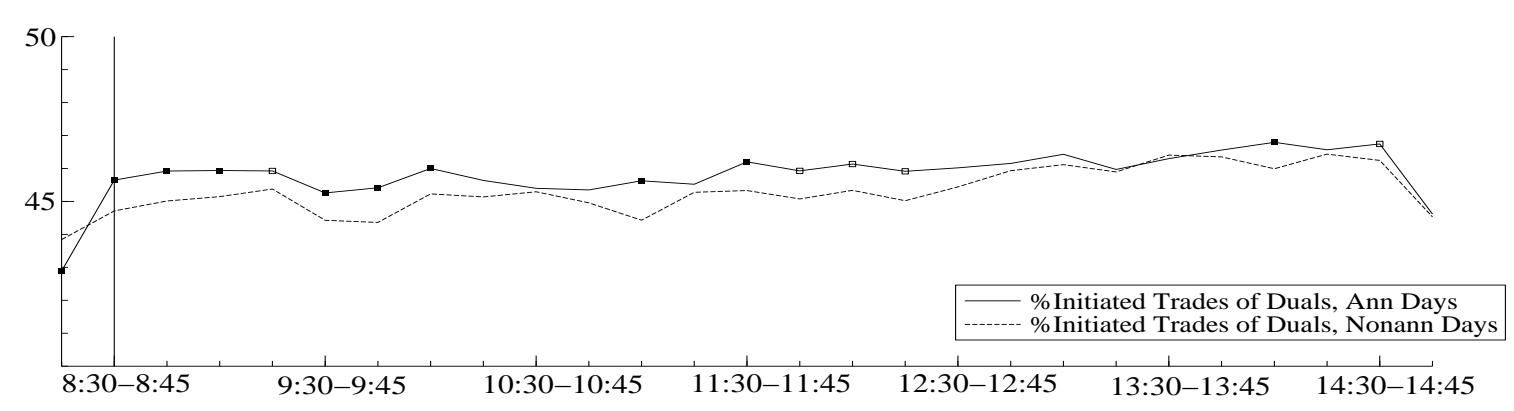

Figure 3 shows the intraday pattern of the percentage of the market makers' trades 
that they initiate. On each day and in each 15 minute interval we calculate the total number of proprietary trades in which market makers are involved. Then we use the buyer- or seller-initiated indicator that we obtain from our state space form regime switching signing methodology from Section 3 and match it to the buy/sell indicator in our dataset. If these agree (thus, e.g., if the trade is buyer-initiated and the data indicates the floor trader bought) we label the trade as being initiated by a market maker. We then calculate the number of initiated market maker trades as a percentage of the total number of market maker trades. In Panel (A) we look at this variable for locals, in Panel (B) for duals.

For both locals and duals the percentage of initiated trades is high. On average market makers initiate more than $45 \%$ of their trades. As the trades are two-sided the maximum percentage for all market makers we could have here is $50 \%$. That the percentage of initiated trades is close to this number indicates that market makers also demand liquidity for a significant part of the day.

That this percentage is high contradicts the assumption in classic market making models that the market maker is a passive liquidity supplier. However, it is not inconsistent with other economic theories. For example, in the 'hot-potato' trading model of Lyons (1997) in the first stage market makers trade with the general public and absorb their order flow. In the second stage in multiple rounds the market makers offset their inventory position by engaging in interdealer trading. Thus, one outside order brought to the market results in multiple trades on the interdealer market, consistent with a high percentage of initiated market maker trades. The percentage of initiated trades is higher for local traders than for dual traders, $48 \%$ and $45 \%$ respectively. Interestingly, the difference in this percentage between days when information is coming to the market compared to nonannouncement days is most significant for the dual traders in the post-announcement interval. These results are consistent either with the market makers being active in managing their inventory positions, or with them being active in building up speculative positions. In addition, the significant difference for dual traders in the half hour after macroeconomic announcements indicates they change their behavior shortly after there is information coming to the market. To study these issues further we look at the inventory positions of the market makers.

\subsection{Market Maker Inventory and Macro News}

In Figure 4 we show the inventory position, calculated as described in Section 2, of the market makers at four occasions in the day. We focus on differences in inventory positions 


\section{Figure 4: Inventory Positions over Day, Three Types of Announcements}

The figure reports the distribution of inventory positions for different times in the day on three type of announcement days and on nonannouncement days for floor traders active in the 30Y treasury futures in 19941997. For each time point the inventory position is calculated only for traders that were active before that time, assuming a zero inventory position at the beginning of the day. On announcement days, the distribution of inventory is calculated separately for three groups of announcements: all announcements (indicated by All Announcement Days), Nonfarm payroll employment, CPI and PPI announcements (indicated by Nonfarm, CPI, PPI Ann Days) and Nonfarm payroll announcements only (indicated by Nonfarm Payroll Emp Ann Days). The distribution is shown for four time points in the day: 8:30, 8:45, 9:00 and the end of the trading day $(E o D)$.
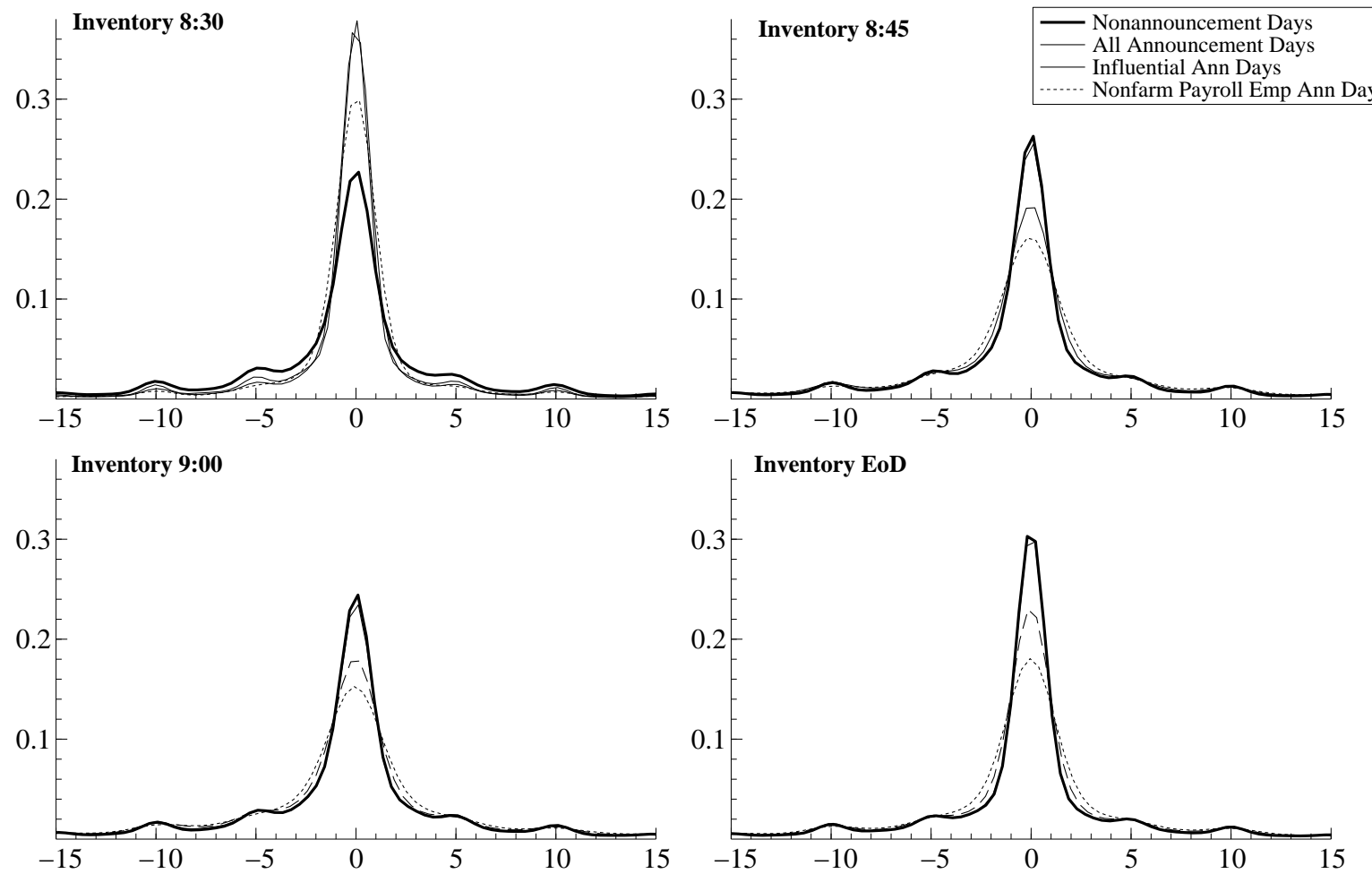
between announcement and nonannouncement days. As we only consider macroeconomic announcements that occur at 8:30 we show the inventory positions around this time. Specifically, we show the empirical distribution of trader inventories at 8:30 (shortly before the news is released), the inventory position at 8:45, at 9:00 and finally at the end of the trading day.

From Figure 4 it is clear that the market makers prefer to have zero inventory positions just prior to announcements (i.e. they like to 'go in flat'). In particular, the inventory distribution on nonannouncement days at 8:30 (the bold line) is much more dispersed than the distribution on announcement days. Immediately after the announcement the market makers quickly build up inventory positions: compared to nonannouncement days the empirical inventory distribution is more dispersed.

For robustness, we also report results for the set of the three most influential announcement days (the nonfarm, CPI and PPI announcement, see, e.g., Green (2004), Pasquariello and Vega (2007) and Menkveld, Sarkar, and Van der Wel (2007)) as well as the most influential announcement (the nonfarm payroll employment figure). We find that on days with the strongest reactions to the news the distribution of inventory is widest. In addition we estimate the inventory distribution of locals and duals separately (figures available from the authors upon request). The results for these different market maker types show similar patterns, attesting to the robustness of our results.

It remains to be seen however whether these positions are consistent with market maker liquidity supply behavior or speculative position taking. In the first situation the market makers accommodate the desire of the outside customers to trade after announcements by absorbing their trades and in the process thus accumulate an inventory position. In the second situation the inventory position is build up because the market maker exploits a private signal on the movement of the price, and wants to speculate on this.

\subsection{Initiated Traders that Increase Inventory}

To disentangle whether the results so far are consistent with liquidity supply or speculative position taking by market makers we examine the share of the initiated trades from Figure 3 that increases their inventory position. If the large percentage of initiated trades and the increased inventory position after macroeconomic announcements is consistent purely with their market maker liquidity supply role we expect them to only initiate trades that reduce their absolute inventory position. In other words, the market makers will only initiate trades 
that bring them closer to their long-term average inventory position. On the other hand, if we find a high percentage of initiated trades that increase the market makers' absolute inventory position this is consistent with the market makers being informed and speculating on future price movements.

Figure 5: Percentage of Inventory Increasing Trades by Market Makers

These figures show the intraday pattern of the percentage proprietary trades of locals (A) and duals (B) which increase individual traders' inventory positions. We classify traders at the daily basis, and label a trader to be a local (broker) if more than $98 \%$ (less than $2 \%$ ) of his trades are for own account, otherwise he is a dual. We sign data according to our State Space Form Regime Switching methodology and match the obtained buyerand seller-initiated indicator with the buy and sell indicator from our dataset. If they agree we classify the trade as being initiated by the market maker, if they do not agree we classify the trade as being an uninitiated market maker trade. For each interval and trader we then calculate the percentage of total proprietary trades that they initiate and which increase individual traders inventory (labelled as \%initiated inventory increasing trades). The solid (dashed) lines show the intraday pattern for announcement (nonannouncement) days, the solid vertical lines represent the 8:30-8:45 announcement interval. An open (closed) circle indicates a significant difference between announcement and nonannouncement days at the 5\% (1\%) level.

\section{(A) \%Initiated Inventory Increasing Trades of Locals}

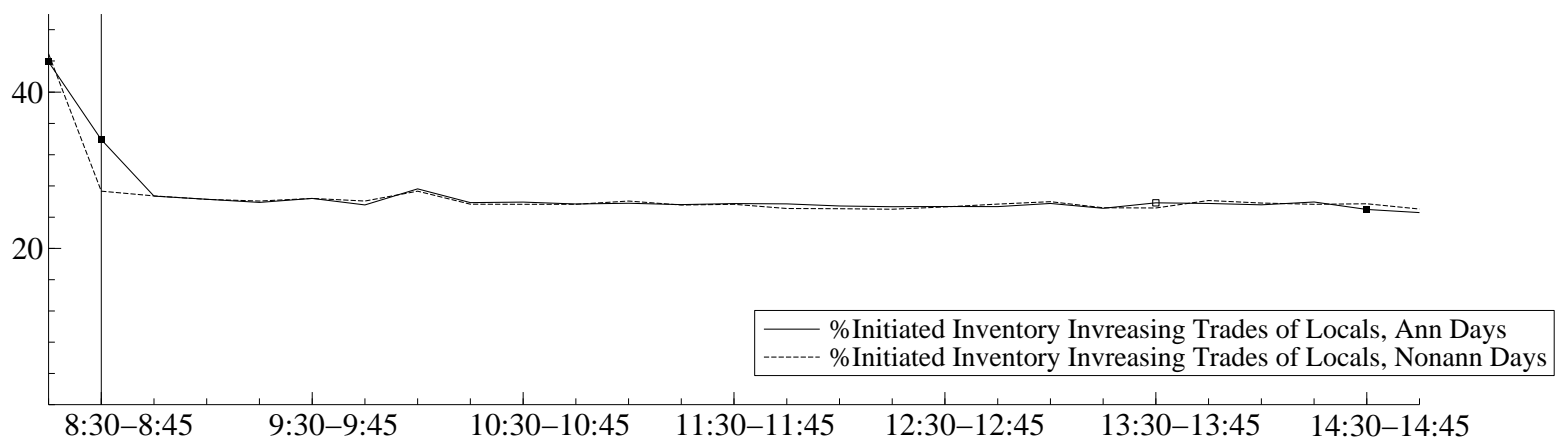

(B) \%Initiated Inventory Increasing Trades of Duals

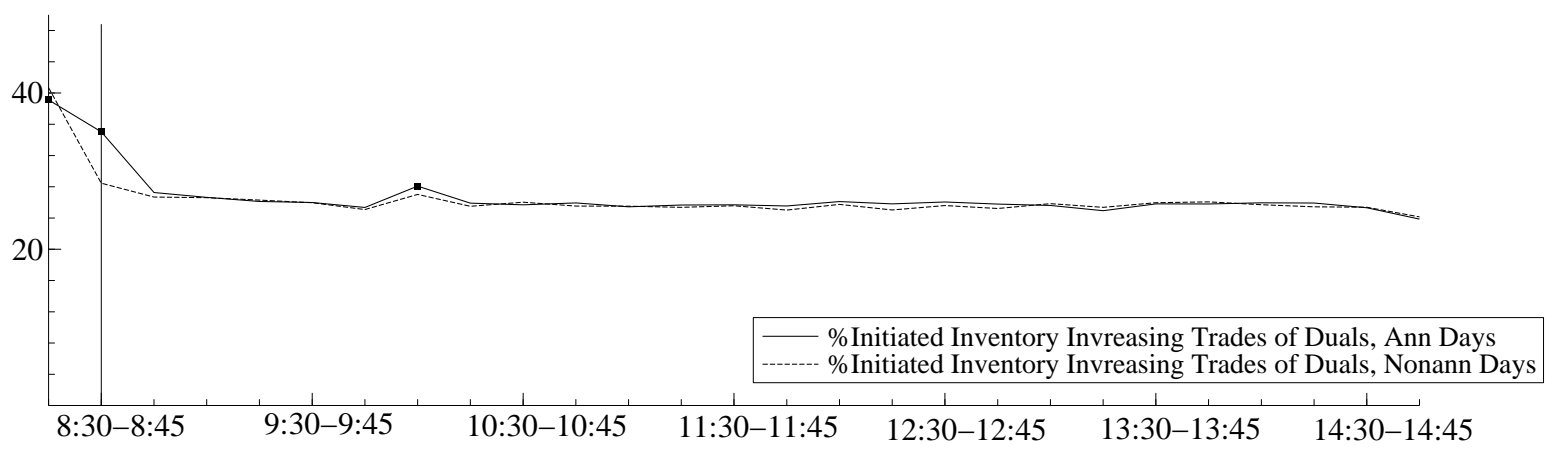


In Figure 5 we split the percentage of initiated trades from Figure 3 to trades that are inventory increasing and those that are inventory decreasing. On each day and in each 15 minute interval we calculate the total number of proprietary trades in which market makers are involved. Then we use the buyer- or seller-initiated indicator that we obtain from our state space form regime switching signing methodology from Section 3 and match it to the buy/sell indicator in our dataset. If these correspond we label the trade as being initiated by a market maker. Then, for each market maker we sum all their signed initiated trades in the interval and see whether they increase their inventory position. We then calculate the number of initiated inventory increasing market maker trades as a percentage of the total number of market maker trades. ${ }^{21}$ In Panel (A) we look at this variable for locals, in Panel (B) for duals.

We find a very high percentage of market maker trades that are initiated and increase individual inventory positions, over 25\%. Unlike the total percentage of initiated trades, which is higher for local traders, the percentage of initiated inventory increasing trades is almost identical for local and dual traders. Interestingly, for both traders there is a significant different percentage of initiated inventory increasing trades in the 8:30-8:45 interval after announcements compared to nonannouncement days. This effect is strongest for the dual traders.

The results in Figure 5 are consistent with the market makers taking on a position after macroeconomic announcements. Both local traders and dual traders do so, but in particular the traders with the additional information from bringing customer orders to the market build up a position after the announcement. The high percentage of initiated inventory increasing trades provides evidence against the market makers being uninformed liquidity suppliers, as pure market makers would only initiate trades that mean revert their inventory.

\footnotetext{
${ }^{21}$ The frequency with which we perform this analysis is low. It is very well possibly that within the 15 minute interval the initiated trades do not only respond to the inventory position at the begin of the interval, but also to uninitiated trades in the interval. We look at 15 minute intervals to ensure that possible errors due to the timing algorithm do not cause our results. In addition we also perform the analysis of this section in 1 minute intervals. This frequency is consistent with Manaster and Mann (1996), who look at inventory management for a similar futures market dataset. Though the percentages of inventory increasing trades are slightly lower we get qualitatively similar results (the corresponding figures are available from the authors upon request).
} 


\subsection{Initiated Inventory Increasing Trades and Trading Profits}

If the market makers indeed take on speculative positions through initiated inventory increasing trades then it is interesting to see if the traders that do so most derive positive profits from this. We examine this by looking in the cross-section of market makers, and relate the percentage of inventory increasing trades to profits from trading. We follow Fishman and Longstaff (1992) and define profitability as:

$$
\pi_{k t}=\frac{\left(\sum_{j=1}^{N_{k t}^{s}} q_{j k t}^{s} P_{j k t}^{s}-\sum_{j=1}^{N_{k t}^{b}} q_{j k t}^{b} P_{j k t}^{b}+\left(\sum_{j=1}^{N_{k t}^{b}} q_{j k t}^{b}-\sum_{j=1}^{N_{k t}^{s}} q_{j k t}^{s}\right) R E F P_{t}\right)}{\max \left(\sum_{j=1}^{N_{k t}^{b}} q_{j k t}^{b}, \sum_{j=1}^{N_{k t}^{s}} q_{j k t}^{s}\right)}
$$

where $\pi_{k t}$ is the profit per round-trip contract ${ }^{22}$ for intermediary $k$ on day $t, N_{k t}^{b}\left(N_{k t}^{s}\right)$ is the total number of buys (sells), $q_{j k t}^{b}\left(q_{j k t}^{s}\right)$ is the quantity of the $j$ th transaction in terms of number of contracts, $P_{j k t}^{b}\left(P_{j k t}^{s}\right)$ is the associated price, and $R E F P_{t}$ is the reference price in day $t$. Similar to the calculation of inventory, the profit calculation assumes that the intermediary starts with zero inventory. The end of day position (if any) is liquidated at a reference price $R E F P_{t}$, which we take to be the daily settlement price.

In Table 4 we split these profits from trading according to the percentage of initiated inventory increasing trades. For each day we calculate the $25 \%$ quantile, median and the $75 \%$ quantile of the percentage of inventory increasing trades and based on this classify the traders and corresponding profits on a daily basis in four groups. Looking at the median, we generally find for both the locals and duals on both announcement and nonannouncement days a positive relation between the percentage of initiated inventory increasing trades and trading profits. ${ }^{23}$ Moreover, the results do not only seem to be in the median, also in the lower quantiles similar patterns can be found. Thus not only do market makers who have a large percentage of initiated inventory increasing trades earn higher profits from trading on average, they reduce the downside of their profits.

We therefore conclude that for locals and duals on announcements days there indeed is a positive and significant relation between inventory increasing trades and profits from trading, with the strongest relation for the dual traders. These results are consistent with the market makers building up a position after the announcement, and earning a profit from

\footnotetext{
${ }^{22}$ We use a per-contract profit measure to control for trade activity, as locals are more active than duals.

${ }^{23}$ For the dual traders the pattern is not always monotonous, which is in part caused by traders that are very inactive. For example, traders that only trade once on a day are automatically put in either the smallest or largest group, as either $0 \%$ or $100 \%$ of their trades are initiated inventory increasing.
} 
Table 4: Own-Account Trading Profits and Inventory Increasing Trades

This table reports summary statistics on the cross-sectional distribution of proprietary trading profits split to percentage of trades that increase trader inventory for both locals and duals. We classify traders at the daily basis, and label a trader to be a local (broker) if more than $98 \%$ (less than $2 \%$ ) of his trades are for own account, otherwise he is a dual. To obtain the profits per contract traded round trip for each trader we subtract the value of purchases from the value of sales and add the value of end-of-period inventory (assuming zero inventory at the start). We divide this by the total number of contracts traded to arrive at a profit per contract traded round trip. We split these profits according to percentage of initiated inventory increasing trades (\%iiit). That is, for each day we calculate the $25 \%$ quantile $(Q(25 \%)$ ), the median and the $75 \%$ quantile $(Q(75 \%))$ of the percentage of initiated inventory increasing trades and based on this classify daily the traders and corresponding profits in four groups. We show the mean, standard deviation (St Dev) and the three quartiles (25\% Quant, Median and 75\% Quant) of the cross-sectional distribution (across intermediaries) of own-account trading profits (with the number of trader days in each group in the column \#Trader Days).

\begin{tabular}{|c|c|c|c|c|c|c|}
\hline \multicolumn{7}{|c|}{ Trading Profits split to \%Initiated Inventory Increasing Trades (\%iiit) } \\
\hline & \multicolumn{2}{|c|}{ \#Trader } & \multicolumn{3}{|c|}{$25 \%$} & $75 \%$ \\
\hline & Days & Mean & St Dev & Quant & Median & Quant \\
\hline \multicolumn{7}{|l|}{ Local Traders } \\
\hline \multicolumn{7}{|l|}{ announcement days } \\
\hline$\%$ iiit $<\mathrm{Q}(25 \%)$ & 27,868 & 5.9 & 158.1 & -9.9 & 5.1 & 21.5 \\
\hline $\mathrm{Q}(25 \%) \leq \%$ iiit $<$ Median & 27,748 & 5.4 & 67.3 & -3.4 & 5.7 & 15.4 \\
\hline Median $\leq \%$ iiit $<\mathrm{Q}(75 \%)$ & 27,842 & 6.7 & 78.3 & -1.3 & 6.5 & 15.4 \\
\hline$\%$ iiit $\geq \bar{Q}(75 \%)$ & 28,187 & 5.1 & 165.7 & -2.7 & 6.7 & 19.2 \\
\hline \multicolumn{7}{|l|}{ nonannouncement days } \\
\hline$\%$ iiit $<\mathrm{Q}(25 \%)$ & 24,028 & 3.7 & 133.7 & -11.1 & 4.4 & 20.2 \\
\hline $\mathrm{Q}(25 \%) \leq \%$ iiit $<$ Median & 24,081 & 4.9 & 63.1 & -4.2 & 4.9 & 14.5 \\
\hline Median $\leq \%$ iiit $<\mathrm{Q}(75 \%)$ & 24,096 & 6.5 & 63.4 & -2.1 & 5.7 & 14.3 \\
\hline$\%$ iiit $\geq \bar{Q}(75 \%)$ & 24,469 & 6.0 & 146.6 & -4.6 & 5.5 & 17.4 \\
\hline \multicolumn{7}{|l|}{ Dual Traders } \\
\hline \multicolumn{7}{|l|}{ announcement days } \\
\hline \%iiit $<\mathrm{Q}(25 \%)$ & 14,658 & 5.9 & 89.7 & -9.6 & 8.1 & 25.3 \\
\hline $\mathrm{Q}(25 \%) \leq \%$ iiit $<$ Median & 14,624 & 8.4 & 59.0 & -3.6 & 9.1 & 21.4 \\
\hline Median $\leq \%$ iiit $<\mathrm{Q}(75 \%)$ & 14,729 & 9.3 & 57.2 & -0.7 & 9.2 & 19.9 \\
\hline$\%$ iiit $\geq Q(75 \%)$ & 15,188 & 10.3 & 84.0 & -0.0 & 8.2 & 19.4 \\
\hline \multicolumn{7}{|l|}{ nonannouncement days } \\
\hline$\%$ iiit $<\mathrm{Q}(25 \%)$ & 13,025 & 5.1 & 79.0 & -9.6 & 7.8 & 24.0 \\
\hline $\mathrm{Q}(25 \%) \leq \%$ iiit $<$ Median & 12,978 & 6.7 & 50.0 & -4.1 & 8.2 & 19.6 \\
\hline Median $\leq \%$ iiit $<\mathrm{Q}(75 \%)$ & 13,060 & 8.0 & 50.2 & -1.8 & 8.3 & 18.5 \\
\hline$\%$ iiit $\geq \bar{Q}(75 \%)$ & 13,601 & 5.8 & 70.5 & -1.4 & 6.8 & 17.0 \\
\hline
\end{tabular}


this. The market makers that have the highest percentage of inventory increasing trades earn the highest profits. This relation is strongest for dual traders, the group of market makers with the additional information set of observing what orders customers bring to the market.

\section{Conclusion}

We propose a new method to determine the initiating party of a trade. Hasbrouck (2004) suggests a Bayesian method to do this in a market setting in which quotes are not available. As this method is numerically expensive it may not be feasible for datasets of highly active markets. We develop an alternative likelihood-based approach to sign trades in the absence of quotes. Simulation results show similar desirable properties in terms of efficiency, but increased speed. We also propose a modified version that allows for two other features common to financial market datasets: multiple trades occurring at the same time and a trade time that is observed with noise.

We apply the method to the $30 \mathrm{Y}$ U.S. treasury futures market and study liquidity supply by market makers. Classic models assume he is an uninformed passive liquidity supplier who actively manages his inventory. So far, the empirical support is weak. We find that market makers initiate a significant amount of trades that increase their inventory positions. When we look at the cross-section of market makers and relate the extent to which their initiated trades are inventory increasing to their profits from trading, we find a significant and positive relation. Our results provide evidence against the market maker being just an uninformed liquidity supplier. On the contrary, he seems to actively speculate on private information signals. Our results stress the need for the development of theoretical models in which the market maker is informed, such as the recent Boulatov and George (2008) model.

\section{Appendix}

In this appendix we describe the recursions of the filtering algorithm used to make inferences on the state space form regime switching representation of the Roll (1984) model as in equation (3). For illustrative purposes we first detail these recursions for a case without regime switching, the univariate case of the Gaussian approximation of the Roll (1984) model from equation (4). 


\section{Recursions for Linear State Space Model}

The univariate version of the Gaussian approximation of the Roll (1984) model is given by:

$$
\begin{aligned}
p_{t} & =m_{t}+v_{t}, & & v_{t} \sim N\left(0, \sigma_{v}^{2}\right), \\
m_{t} & =m_{t-1}+u_{t}, & & u_{t} \sim N\left(0, \sigma_{u}^{2}\right),
\end{aligned}
$$

for $t=1, \ldots, n$ and with $p_{t}$ the observed log price series and $m_{t}$ the unobserved log efficient price of the asset. In here $\sigma_{v}^{2}$ and $\sigma_{u}^{2}$ are parameters, with the former representing the spread (in effect approximating the binary $c q_{t}$ from the Roll (1984) model with a Gaussian distribution) and the latter the log efficient price innovation. We are interested in obtaining estimates of these parameters and the log efficient price series, conditional on all data. To do this we rely on standard linear Gaussian state space techniques, such as detailed in Durbin and Koopman (2001) and Kim and Nelson (1999). In particular, we use the Kalman filter for this. Following the terminology in these references, the latent $m_{t}$ is often referred to as the unobserved 'state' of the observed price process.

To initiate the Kalman filter we need to take a distribution for the first efficient price: $m_{1} \sim$ $N\left(a_{1}, P_{1}\right)$. In case little is known about this we can make this a very uninformative distribution, by setting $P_{1}$ to be large. ${ }^{24}$ Then for every time $t$ we first calculate the estimated unobserved efficient price based on all data up to and including the previous period (which is referred to as the 'predicted state'). In the second step, we obtain the estimated unobserved efficient price based on all data up to and including this period (referred to as the 'filtered state'). We have:

$$
\begin{aligned}
m_{t \mid t-1} & = \begin{cases}a_{1} & t=1 \\
m_{t-1 \mid t-1} & t>1\end{cases} \\
P_{t \mid t-1} & = \begin{cases}P_{1} & t=1 \\
P_{t-1 \mid t-1}+\sigma_{u}^{2} & t>1\end{cases} \\
f_{t} & =p_{t}-m_{t \mid t-1}, \\
F_{t} & =P_{t \mid t-1}+\sigma_{v}^{2}, \\
m_{t \mid t} & =m_{t \mid t-1}+P_{t \mid t-1} F_{t}^{-1} f_{t} \\
P_{t \mid t} & =P_{t \mid t-1}-P_{t \mid t-1} F_{t}^{-1} P_{t \mid t-1},
\end{aligned}
$$

with $m_{t \mid t-1}\left(P_{t \mid t-1}\right)$ the predicted state (and its variance), $m_{t \mid t}\left(P_{t \mid t}\right)$ the filtered state (and its variance) and $f_{t}\left(F_{t}\right)$ the Kalman filter residual (and its variance). To obtain estimates of the log efficient price conditional on all data (referred to as the 'smoothed state') we need to do a backward loop, known as the Kalman Smoother:

$$
\begin{aligned}
m_{t \mid n} & = \begin{cases}m_{t \mid n} & t=n, \\
m_{t \mid t}+P_{t \mid t} P_{t+1 \mid t}^{-1}\left(m_{t+1 \mid n}-m_{t+1 \mid t}\right) & t \leq n-1,\end{cases} \\
P_{t \mid n} & = \begin{cases}P_{t \mid n} & t=n, \\
P_{t \mid t}+P_{t \mid t} P_{t+1 \mid t}^{-1}\left(P_{t+1 \mid n}-P_{t+1 \mid t}\right) P_{t+1 \mid t}^{-1} P_{t \mid t} & t \leq n-1,\end{cases}
\end{aligned}
$$

with $m_{t \mid n}\left(P_{t \mid n}\right)$ the smoothed state (and its variance).

As pointed out above, the goal of the analysis is to make inferences about the parameters and the unobserved states. To this end we need to derive the likelihood

$$
L\left(\sigma_{v}^{2}, \sigma_{u}^{2} \mid p_{1}, \ldots, p_{n}\right)=f\left(p_{1}, \ldots, p_{n} \mid \sigma_{v}^{2}, \sigma_{u}^{2}\right)
$$

\footnotetext{
${ }^{24}$ In the extreme case, $P_{1} \rightarrow \infty$, the Kalman filter is said to have a diffuse initial distribution.
} 
We use

$$
f\left(p_{1}, \ldots, p_{n} \mid \sigma_{v}^{2}, \sigma_{u}^{2}\right)=\prod_{t=2}^{n} f\left(p_{t} \mid p_{1}, \ldots, p_{t-1}, \sigma_{v}^{2}, \sigma_{u}^{2}\right) f\left(p_{1} \mid \sigma_{v}^{2}, \sigma_{u}^{2}\right) .
$$

We follow the standard approach in econometrics to maximize the log of the likelihood rather than the likelihood, such that we obtain:

$$
\ln \left(f\left(p_{1}, \ldots, p_{n} \mid \sigma_{v}^{2}, \sigma_{u}^{2}\right)\right)=\ln \left(f\left(p_{1} \mid \sigma_{v}^{2}, \sigma_{u}^{2}\right)\right)+\sum_{t=2}^{n} \ln \left(f\left(p_{t} \mid p_{1}, \ldots, p_{t-1}, \sigma_{v}^{2}, \sigma_{u}^{2}\right)\right) .
$$

We evaluate $\ln \left(f\left(p_{t} \mid p_{1}, \ldots, p_{t-1}, \sigma_{v}^{2}, \sigma_{u}^{2}\right)\right)$ using the output from the Kalman filter. Following Durbin and Koopman (2001) we obtain:

$$
\ln \left(f\left(p_{t} \mid p_{1}, \ldots, p_{t-1}, \sigma_{v}^{2}, \sigma_{u}^{2}\right)\right)=-\ln (2 \pi) / 2-\ln \left(F_{t}\right) / 2+f_{t}^{2} F_{t}^{-1} / 2 .
$$

From this it is clear that evaluating the loglikelihood through the Kalman filter is straightforward. After initializing the likelihood for the first observation we simply add the above term at every time $t$.

The derivation of the Kalman filter and likelihood strongly relies on linearity and normality. In calculating the filtered state $m_{t \mid t}$ and its variance $P_{t \mid t}$ we use the convenient properties of the bivariate normal distribution. If $v_{t}$ and $u_{t}$ are not normal the derivation no longer holds and we face a problem. ${ }^{25}$ Typically researchers use computationally expensive simulation based techniques, such as Importance Sampling (see Durbin and Koopman (2001, Part II)), to deal with this. However, in the next subsection we discuss an algorithm that can be used when some of the distributions are binary instead of Gaussian. This technique for this special situation has the advantage that it does not rely on simulation based methods.

\section{Recursions for State Space Model with Regime Switching}

The state space form regime switching representation of the Roll (1984) model is:

$$
\begin{array}{lll}
p_{t}=m_{t}+c q_{t}, & & q_{t} \in\{-1,+1\}, \\
m_{t}=m_{t-1}+u_{t}, & & u_{t} \sim N\left(0, \sigma_{u}^{2}\right) .
\end{array}
$$

with $p_{t}$ the observed log price series, $m_{t}$ the unobserved log efficient price of the asset and $q_{t}$ the unobserved time series of trade signs. In here $c$ and $\sigma_{u}^{2}$ are parameters, with the former representing the half-spread and the latter the $\log$ efficient price innovation. We are interested in obtaining estimates of these parameters, the log efficient price series and the sign time series, conditional on all data.

As we point out in the previous subsection, to do this we can no longer rely on standard linear Gaussian state space techniques. Fortunately, for the special set-up of the Roll (1984) model we have a likelihood based alternative to the simulation techniques that typically need to be used for non-Gaussian state space models. As discussed in Section 3, we work from regime switching models in state space form, such as detailed in Kim and Nelson (1999). The associated techniques are frequently used by macroeconomists to model time series which process depends on whether the economy is in the state of recession or expansion. The idea is to integrate over the unobserved binary distributed variables. Conditional on a time series of trade initiating signs $q_{t}, t=1, \ldots, n$, the Roll (1984) model is again a linear Gaussian model. There is one complication with this approach, which we elaborate on when we encounter it in the description below. The recursions in this section describing the technique closely follow Kim and Nelson (1999, Chapter 5).

\footnotetext{
${ }^{25}$ In the non-Gaussian case the filtered estimate obtained from the Kalman filter is no longer the minimum mean square estimator. It is however the minimum mean square linear estimator, as Duncan and Horn (1972) point out.
} 
At each point in time we analyze the model in three stages, with an initialization for the first observation. Similar to the linear Gaussian model from the previous section, in the initialization of the system we get $f\left(p_{1} \mid c, \sigma_{u}^{2}\right)$. However, as there are two possibilities for the first trade (buyer- or seller-initiated, $q_{1}=+1$ or $q_{1}=-1$ respectively) we need two initial conditions. For both cases we use the same initialization as in the previous section. In addition we need an initial probability that the first trade is buyer-initiated, which we set to be 0.5 following the Roll (1984) model: $\mathbb{P}\left(q_{1}=+1\right)=0.5$.

In the first stage we evaluate the Kalman filter, with recursions similar to the previous section. For example, for the first three periods we have:

$$
\begin{aligned}
& t=1\left\{\begin{aligned}
m_{1 \mid 0}^{i} & =a_{1}^{i}, & P_{1 \mid 0}^{i} & =P_{1}^{i}, \\
f_{1}^{i} & =p_{1}-m_{1 \mid 0}^{i}-q_{1} c, & F_{1}^{i} & =P_{1 \mid 0}^{i}, \\
m_{1 \mid 1}^{i} & =m_{1 \mid 0}^{i}+P_{1 \mid 0}^{i}\left(F_{1}^{i}\right)^{-1} f_{1}^{i}, & P_{1 \mid 1}^{i} & =P_{1 \mid 0}^{i}-P_{1 \mid 0}^{i}\left(F_{1}^{i}\right)^{-1} P_{1 \mid 0}^{i},
\end{aligned}\right. \\
& t=2\left\{\begin{aligned}
m_{2 \mid 1}^{i, j} & =m_{1 \mid 1}^{i}, & P_{2 \mid 1}^{i, j} & =P_{1 \mid 1}^{i}+\sigma_{u}^{2}, \\
f_{2}^{i, j} & =p_{2}-m_{2 \mid 1}^{i, j}-q_{2} c, & F_{2}^{i, j} & =P_{2 \mid 1}^{i, j} \\
m_{2 \mid 2}^{i, j} & =m_{2 \mid 1}^{i, j}+P_{2 \mid 1}^{i, j}\left(F_{2}^{i, j}\right)^{-1} f_{2}^{i, j}, & P_{2 \mid 2}^{i, j} & =P_{2 \mid 1}^{i, j}-P_{2 \mid 1}^{i, j}\left(F_{2}^{i, j}\right)^{-1} P_{2 \mid 1}^{i, j},
\end{aligned}\right. \\
& t=3\left\{\begin{aligned}
m_{3 \mid 2}^{i, j, k} & =m_{2 \mid 2}^{i, j}, & P_{3 \mid 2}^{i, j, k} & =P_{2 \mid 2}^{i, j}+\sigma_{u}^{2}, \\
f_{3}^{i, j, k} & =p_{3}-m_{3 \mid 2}^{i, j, k}-q_{3} c, & F_{3}^{i, j, k} & =P_{3 \mid 2}^{i, j, k}, \\
m_{3 \mid 3}^{i, j, k} & =m_{3 \mid 2}^{i, j, k}+P_{3 \mid 2}^{i, j, k}\left(F_{3}^{i, j, k}\right)^{-1} f_{3}^{i, j, k}, & P_{3 \mid 3}^{i, j, k} & =P_{3 \mid 2}^{i, j, k}-P_{3 \mid 2}^{i, j, k}\left(F_{3}^{i, j, k}\right)^{-1} P_{3 \mid 2}^{i, j, k},
\end{aligned}\right.
\end{aligned}
$$

where $i \in\left\{q_{1}=+1, q_{1}=-1\right\}, j \in\left\{q_{2}=+1, q_{2}=-1\right\}$ and $k \in\left\{q_{3}=+1, q_{3}=-1\right\}$. In the Kalman filter we need the previous filtered state to obtain the current predicted state. As we integrate out over the discrete $q_{t}$ this will however make the number of possible paths too large. At time $t$ we do not only need to know $q_{t}$ and $q_{t-1}$, but also $q_{t-2}, q_{t-3}$, etc. This means that at time $t$ there are $2^{t}$ possible paths. To overcome this we collapse the filtered state in the state space form regime switching filter. If we do so we do not need to consider the whole past of the trade sign time series $q_{t}, q_{t-1}, q_{t-2}, \ldots, q_{1}$, but only $q_{t}$ and $q_{t-1}$. With this approximation we follow the recommendation of $\operatorname{Kim}\left(1994\right.$, p.9), to "... carry at least $M^{r+1}$ states at each iteration", with $M$ the number of states and $r$ the number of lags appearing in the state-space representation. ${ }^{26}$

Based on this approximation we thus focus on four possible cases in the first stage of the filter: (1) the current and previous trade being buyer-initiated $\left(q_{t}=+1 ; q_{t-1}=+1\right)$; (2) the current trade being buyer-initiated and the previous seller-initiated $\left(q_{t}=+1 ; q_{t-1}=-1\right)$; $(3)$ the current trade being sellerinitiated and the previous buyer-initiated $\left(q_{t}=-1 ; q_{t-1}=+1\right)$; and $(4)$ the current and previous trade being seller-initiated $\left(q_{t}=-1 ; q_{t-1}=-1\right)$. Thus, in this first stage we obtain $m_{t \mid t-1}^{i, j}, P_{t \mid t-1}^{i, j}, f_{t}^{i, j}, F_{t}^{i, j}, K_{t}^{i, j}$, $m_{t \mid t}^{i, j}$ and $P_{t \mid t}^{i, j}$ for $i \in\left\{q_{t-1}=+1, q_{t-1}=-1\right\}$ and $j \in\left\{q_{t}=+1, q_{t}=-1\right\}$.

In the second stage we look at the probability of each of the states, given our output of the Kalman filter from these four possible cases. This methodology follows the Hamilton (1989) filter. In particular, for

\footnotetext{
${ }^{26}$ Other approximations are possible. For example, it is possible to collapse the filtered state into one value and thus only record $q_{t}$. Or, instead of only using $q_{t}$ and $q_{t-1}$ we can in addition also consider $q_{t-2}$. However, according to Kim's recommendation we are already rather conservative: if we follow his recommendation we should consider only 2 states whereas we look at 4 states.
} 
the Roll (1984) model we have:

$$
\begin{aligned}
\mathbb{P}\left(q_{t}, q_{t-1} \mid p_{1}, \ldots, p_{t-1}\right) & =\mathbb{P}\left(q_{t} \mid q_{t-1}\right) \mathbb{P}\left(q_{t-1} \mid p_{1}, \ldots, p_{t-1}\right)=0.5 \mathbb{P}\left(q_{t-1} \mid p_{1}, \ldots, p_{t-1}\right), \\
f\left(p_{t} \mid p_{1}, \ldots, p_{t-1}\right) & =\sum_{q_{t}} \sum_{q_{t-1}} f\left(p_{t}, q_{t}, q_{t-1} \mid p_{1}, \ldots, p_{t-1}\right), \\
l i k+ & =\sum_{q_{t}} \sum_{q_{t-1}} f\left(p_{t} \mid q_{t}, q_{t-1}, p_{1}, \ldots, p_{t-1}\right) \mathbb{P}\left(q_{t}, q_{t-1} \mid p_{1}, \ldots, p_{t-1}\right), \\
\mathbb{P}\left(q_{t}, q_{t-1} \mid p_{1}, \ldots, p_{t}\right) & =\frac{f\left(p_{t}, q_{t}, q_{t-1} \mid p_{1}, \ldots, p_{t-1}\right)}{f\left(p_{t} \mid p_{1}, \ldots, p_{t-1}\right)}, \\
& =\frac{f\left(p_{t} \mid q_{t}, q_{t-1}, p_{1}, \ldots, p_{t-1}\right) \mathbb{P}\left(q_{t}, q_{t-1} \mid p_{1}, \ldots, p_{t-1}\right)}{f\left(p_{t} \mid p_{1}, \ldots, p_{t-1}\right)}, \\
\mathbb{P}\left(q_{t} \mid p_{1}, \ldots, p_{t}\right) & =\sum_{q_{t-1}} \mathbb{P}\left(q_{t}, q_{t-1} \mid p_{1}, \ldots, p_{t}\right),
\end{aligned}
$$

where $f\left(p_{t} \mid q_{t}, q_{t-1}, p_{1}, \ldots, p_{t-1}\right)$ can be evaluated from the prediction error decomposition using the output of the Kalman filter at time $t$ :

$$
f\left(p_{t} \mid q_{t}, q_{t-1}, p_{1}, \ldots, p_{t-1}\right)=(2 \pi)^{-n / 2}\left|F_{t}^{i, j}\right|^{-1 / 2} e^{-\left(f_{t}^{i, j}\right)^{\prime}\left(F_{t}^{i, j}\right)^{-1} f_{t}^{i, j} / 2},
$$

which is evaluated for $i \in\left\{q_{t-1}=+1, q_{t-1}=-1\right\}$ and $j \in\left\{q_{t}=+1, q_{t}=-1\right\}$.

Then, in the third stage for each time point, we follow Kim (1994) and do the aforementioned collapsing of the filtered state. As pointed out above, this is done to overcome the problem that at each point in time we have two possible states due to which the total number of paths will rapidly increase: at time $t$ there are $2^{t}$ possibilities. This is the one approximation we need to keep the filtering analysis tractable. We collapse the filter as follows:

$$
\begin{aligned}
m_{t \mid t}^{j} & =\frac{\sum_{i} \mathbb{P}\left(q_{t}=j, q_{t-1}=i \mid p_{1}, \ldots, p_{t}\right) m_{t \mid t}^{i, j}}{\mathbb{P}\left(q_{t}=j \mid p_{1}, \ldots, p_{t}\right)} \\
P_{t \mid t}^{j} & =\frac{\sum_{i} \mathbb{P}\left(q_{t}=j, q_{t-1}=i \mid p_{1}, \ldots, p_{t}\right)\left(P_{t \mid t}^{i, j}+\left(m_{t \mid t}^{j}-m_{t \mid t}^{i, j}\right)^{2}\right)}{\mathbb{P}\left(q_{t}=j \mid p_{1}, \ldots, p_{t}\right)} .
\end{aligned}
$$

Note that we indeed reduce the dimensionality, as from the Kalman filter we obtain $m_{t \mid t}^{i, j}$ and $P_{t \mid t}^{i, j}$ for $i \in\left\{q_{t-1}=+1, q_{t-1}=-1\right\}$ and $j \in\left\{q_{t}=+1, q_{t}=-1\right\}$, whereas we now have $m_{t \mid t}^{j}$ and $P_{t \mid t}^{j}$ for $j \in\left\{q_{t}=\right.$ $\left.+1, q_{t}=-1\right\}$. In effect the variable $m_{t \mid t}^{j}$ is a mixture of normals. As a result of the approximation $m_{t \mid t}^{i, j}$ can be interpreted as the linear projection of $m_{t}$ on $p_{t}$ and $m_{t-1 \mid t-1}^{i}$.

The procedure above details the calculations in each of the three stages for each time point in the forward loop of the filter. To obtain estimates of the unobserved log efficient price and trade sign time series conditional on all observations we need to follow these with the backward recursions for the smoother. This also consists of three stages, which differ slightly from those of the filtering algorithm. First, we calculate the smoothed probability for being in a certain state:

$$
\begin{aligned}
\mathbb{P}\left(q_{t}=j, q_{t+1}=k \mid p_{1}, \ldots, p_{n}\right) & =\frac{\mathbb{P}\left(q_{t+1}=k \mid p_{1}, \ldots, p_{n}\right) \cdot \mathbb{P}\left(q_{t}=j \mid p_{1}, \ldots, p_{t}\right) \cdot 0.5}{\mathbb{P}\left(q_{t+1}=k \mid p_{1}, \ldots, p_{t}\right)} \\
\mathbb{P}\left(q_{t}=j \mid p_{1}, \ldots, p_{n}\right) & =\sum_{k} \mathbb{P}\left(q_{t}=j, q_{t+1}=k \mid p_{1}, \ldots, p_{n}\right) .
\end{aligned}
$$

Next, we use the smoothing recursion similar to that of the linear Gaussian model to obtain smoothed values 
for the efficient price (and the variance thereof). There are again four cases, now depending on the current state (at time $t$ ) and the next state (time $t+1$ ). When we obtain $m_{t \mid n}^{j, k}$ and $P_{t \mid n}^{j, k}$ for $j \in\left\{q_{t}=+1, q_{t}=-1\right\}$ and $k \in\left\{q_{t+1}=+1, q_{t+1}=-1\right\}$ we use the state probabilities to obtain smoothed values for the unobserved log efficient price conditional on it being in a certain state:

$$
\begin{aligned}
m_{t \mid n}^{j} & =\frac{\sum_{k} \mathbb{P}\left(q_{t}=j, q_{t+1}=k \mid p_{1}, \ldots, p_{n}\right) m_{t \mid n}^{j, k}}{\mathbb{P}\left(q_{t}=j \mid p_{1}, \ldots, p_{n}\right)} \\
P_{t \mid n}^{j} & =\frac{\sum_{k} \mathbb{P}\left(q_{t}=j, q_{t+1}=k \mid p_{1}, \ldots, p_{t}\right)\left(P_{t \mid n}^{j, k}+\left(m_{t \mid n}^{j}-m_{t \mid n}^{j, k}\right)^{2}\right)}{\mathbb{P}\left(q_{t}=j \mid p_{1}, \ldots, p_{n}\right)} .
\end{aligned}
$$

Finally, we obtain an estimate of the unobserved log efficient price that is not conditional on being in a certain state:

$$
m_{t \mid n}=\sum_{j} \mathbb{P}\left(q_{t}=j \mid p_{1}, \ldots, p_{n}\right) m_{t \mid n}^{j}
$$

\section{References}

Anand, A., and A. Subrahmanyam. 2008. "Information and the intermediary: Are market intermediaries informed traders in electronic markets?" Journal of Financial and Quantitative Analysis 43:p1-28.

Andersen, T.G., T. Bollerslev, F.X. Diebold, and C. Vega. 2007. "Real-Time Price Discovery in Stock, Bond and Foreign Exchange Markets." Journal of International Economics 73:p251-277.

Bjønnes, G.H., and D. Rime. 2005. "Dealer Behavior and Trading Systems in Foreign Exchange Markets." Journal of Financial Economics 75:p571-605.

Boulatov, A., and T.J. George. 2008. "Securities Trading when Liquidity Providers are Informed." Working Paper, AFA 2008 paper.

Chakravary, S., and K. Li. 2003. "An Examination of Own Account Trading by Dual Traders in Futures Markets." Journal of Financial Economics 69:p375-397.

Comerton-Forde, C., T. Hendershott, C.M. Jones, P.C. Moulton, and M.S. Seasholes. 2009. "Time Variation in Liquidity: The Role of Market Maker Inventories and Revenues." Journal of Finance (forthcoming).

Demsetz, H. 1968. "The Cost of Transacting." Quarterly Journal of Economics 82:p33-53.

Doornik, J. A. 1998. Object-oriented Matrix Programming Using Ox 2.0. Timberlake.

Duncan, D.B., and S.D. Horn. 1972. "Linear Dynamic Recursive Estimation from the Viewpoint of Regression Analysis." Journal of the American Statistical Association 67:p815-21. 
Durbin, J., and S. J. Koopman. 2001. Time Series Analysis by State Space Methods. Oxford Statistical Science Series.

Ederington, L., and J. Lee. 1993. "How Markets Process Information: News Releases and Volatility." Journal of Finance 45:p1161-1191.

Ellis, K., R. Michaely, and M. O'Hara. 2000. "The Accuracy of Trade Classification Rules: Evidence from Nasdaq." Journal of Financial and Quantitative Analysis 35:p529-552.

Evans, M.D.D., and R.K. Lyons. 2008. "Forecasting Exchange Rates and Fundamentals with Order Flow." Working Paper.

Fishman, J.F., and F.A. Longstaff. 1992. "Dual Trading in Futures Markets." Journal of Finance 47:p643-671.

Fleming, M., and E. Remolona. 1999. "Price Formation and Liquidity in the U.S. Treasury Market: The Response to Public Information." Journal of Finance 54:p1901-1915.

Fleming, M.J., and A. Sarkar. 1999. "Liquidity in U.S. Treasury Spot and Futures Markets." Market Liquidity Research Findings and Selected Policy Implications.

Frino, A., and E. Jarnecic. 2000. "An empirical analysis of the supply of liquidity by locals in futures markets." Pacific-Basin Finance Journal 8:p443-456.

Glosten, L.R., and L.E. Harris. 1988. "Estimating the Components of the Bid-Ask Spread." Journal of Financial Economics 21:p123-142.

Glosten, L.R., and P.R. Milgrom. 1985. "Bid, Ask and Transaction Prices in a Specialist Market with Heterogeneously Informed Traders." Journal of Financial Economics 14:p71-100.

Green, T.C. 2004. "Economic News and the Impact of Trading on Bond Prices." Journal of Finance 59:p1201-1233.

Hamilton, J. 1989. "A New Approach to the Economic Analysis of Nonstationary Time Series and the Business Cycle." Econometrica 57:357-84.

Harris, L.E. 1990. "Statistical Properties of the Roll Serial Covariance Bid-Ask Spread Estimator." Journal of Finance 45:p579-590.

Hasbrouck, J. 1988. "Trades, Quotes, Inventories, and Information." Journal of Financial Economics 22:p229-252.

- 1999. "The Dynamics of Discrete Bid and Ask Quotes." Journal of Finance 54:p2109-2142. 
—. 2002. "Stalking the "Efficient Price" in Market Microstructure Specifications: an Overview." Journal of Financial Markets 5:p329-339.

- 2004. "Liquidity in the Futures Pit: Inferring Market Dynamics from Incomplete Data." Journal of Financial and Quantitative Analysis 39:p305-326.

- 2009. "Trading Costs and Returns for US Equities: Estimating Effective Costs from Daily Data." Journal of Finance (forthcoming).

Hasbrouck, J., and G. Sofianos. 1993. "The Trades of Market Makers: An Empirical Examination of NYSE Specialists." Journal of Finance 48:p1565-1593.

Hendershott, T., C.M. Jones, and A.J. Menkveld. 2007. "Does Algorithmic Trading Improve Liquidity?" Working Paper, WFA 2008 paper.

Hendershott, T., and A.J. Menkveld. 2009. "Price Pressures." Working Paper.

Kim, C. J. 1994. "Dynamic Linear Models with Markov-Switching." Journal of Econometrics 60:p1-22.

Kim, C. J., and C. R. Nelson. 1999. State Space Models with Regime Switching. MIT Press.

Koopman, S. J., N. Shephard, and J. A. Doornik. 1999. "Statistical algorithms for models in state space using SsfPack 2.2." Econometrics Journal 2:p113-166.

Kyle, A.S. 1985. "Continuous Auctions and Insider Trading." Econometrica 53:p1315-1336.

Lee, C.M., and M.J. Ready. 1991. "Inferring the Trade Direction from Intraday Data." Journal of Finance 46:p733-746.

Locke, P.R., and P. Sarajoti. 2004. "Aggresive dealer pricing." The Quarterly Review of Economics and Finance 44:p559-573.

Lyons, R. 1997. "A Simultaneous Trade Model of the Foreign Exchange Hot Potato." Journal of International Economics 42:p275-298.

Madhavan, A., and S. Smidt. 1993. "An Analysis of Changes in Specialist Inventories and Quotations." Journal of Finance 48:p1595-1628.

Manaster, S., and S.C. Mann. 1996. "Life in the Pits: Competitive Market Making and Inventory Control." Review of Financial Studies 9:p953-975.

Menkveld, A.J., S.J. Koopman, and A. Lucas. 2007. "Modelling Round-the-Clock Price Discovery for Cross-Listed Stocks using State Space Methods." Journal of Business and Economic Statistics 25:p213-225.

Menkveld, A.J., A. Sarkar, and M. Van der Wel. 2007. "Discovering the Equilibrium Riskfree Rate." Tinbergen Institute Discussion Paper, EFA 2007 paper. 
O’Hara, M. 1995. Market Microstructure Theory. Blackwell Publishers.

Panayides, M. A. 2007. "Affirmative obligations and market making with inventory." Journal of Financial Economics 86:p513-542.

Pasquariello, P., and C. Vega. 2007. "Informed and Strategic Order Flow in the Bond Market." Review of Financial Studies 20:p1975-2019.

Roll, R. 1984. "A Simple Implicit Measure of the Effective Bid-ask Spread in an Efficient Market." Journal of Finance 39:p1127-1139.

Rosenberg, J.V., and L.G. Traub. 2007. "Price Discovery in the Foreign Currency Futures and Spot Market." Federal Reserve Bank of New York Staff Reports, no. 262.

Stoll, H.R. 1978. "The Supply of Dealer Services in Securities Markets." Journal of Finance 33:p1131-1151. 